\title{
01/RT/17
}

Páipéar Taighde Teicniúil

Research Technical Paper

\section{Investment Fund Risk: The Tale in the Tails}

Frances Shaw \& Peter G. Dunne 


\title{
Investment Fund Risk: The Tale in the Tails
}

\author{
Frances Shaw \& Peter G. Dunne*
}

Jan 2017

\begin{abstract}
Efforts to develop risk assessment metrics for the non-bank financial sector have been given impetus following the post-crisis broadening of the IMF's Financial Stability Assessments and recent efforts by the Financial Stability Board to address structural vulnerabilities from asset management activities. ${ }^{1}$ Using a novel database of investment funds reporting in Ireland, we employ Marginal Expected Shortfall metrics to capture investment fund exposures to pervasive industry-wide tail events. We reveal the primary fund sectors most responsible for widespread extreme return shortfalls. Fund attributes are then used to explain (mostly) the crosssectional variation in marginal expected shortfall using panel regression techniques. We find that leverage, derivative usage, redemption rates, cash holdings, openness and retail investor focus are important factors that consistently explain the variation in fund-specific sensitivity to pervasive tail risk. Finally, we provide new evidence that ex ante exposure to pervasive extreme negative returns explains significantly more of the risk premium implicit in ex post returns than traditional beta.
\end{abstract}

JEL Codes: G15,G23,G28

Keywords: Investment Funds, systemic risk, marginal expected shortfall.

\footnotetext{
*Corresponding author (Statistics Division \& CD Projects) e-mail: peter.dunne@centralbank.ie. Views expressed are those of the authors and do not necessarily represent the views of the Central Bank of Ireland or the ESCB. This research paper has been cleared for publication by Gerard O'Reilly. We sincerely thank Kitty Moloney for in-depth comments on an earlier draft. This paper also benefited from the comments of participants at the following events: IEA Annual Conference 2016, External Seminar - Smurfit Business School 2016, Conference on Non-Bank Financial Intermediation - CBI Jan 2017 and presentation to the Financial Stability Committee - CBI 2017.

${ }^{1}$ See the FSB's Consultative Document, "Proposed Policy Recommendations to Address Structural Vulnerabilities from Asset Management Activities" (2016) and the IMF's "Review of the Financial Sector Assessment Program: Further Adaptation to the Post-Crisis Era" (2014).
} 


\section{Non-Technical Summary}

The aftermath of the financial crisis that began in mid-2007 has been characterised by frequent destabilising investor 'runs'. It is clear that better risk assessment metrics are needed to cater for analysis of such extreme circumstances and to identify whether the design of investment vehicles (and regulations) can be optimised to mitigate the effects of runs. The drive to assess new metrics is also a response to the broadening of formal risk assessment requests by the IMF and Financial Stability Board efforts to address potential structural vulnerabilities from asset management activities.

Marginal Expected Shortfall (MES) is a tail-based risk measure that has been proposed as a component (or relation) of several methodologies aimed at facilitating the identification of systemic risk exposures of banking financial institutions (e.g. SRISK, Systemic Expected Shortfall and Delta-CoVaR). We therefore examine whether MES is suitable for use in the context of investment fund risk assessments. Our analysis suggests that there is wide variation in the sensitivity of different fund types to extreme negative pervasive tail events. We find that leverage explains a significant proportion of cross-sectional variation in tail risk exposure. Other factors that tend to raise exposure to tail risk included high redemption rates, fund-openness and a retail investor focus. Factors that mitigate such exposure include relatively high usage of derivatives and high cash or near-cash holdings.

While exposure to pervasive tail events is normally rewarded with a return premium, we find that funds catering to the retail investor are an important exception to this norm. These funds, controlling for other characteristics, have greater than usual exposure to pervasive tail events combined with statistically lower returns than other fund segments.

The methods applied here, in our view, could be developed as ex ante risk assessment tools. This would involve projecting forward the market and fund-specific expected volatilities and correlations in a manner analogous to the implementation of the SRISK measure by Brownlees and Engle (2012) as part of the VLAB project at NYU for banks. Further refinement of this analysis could help to better identify behaviours, or mandate designs, that eventually result in excessive exposure to (and generation of) systemic risk. This could contribute to the design of fund regulation and help in targeting risk assessments. 


\section{Introduction}

Investment funds are responsible for the allocation of a substantial proportion of all investment capital that is sought by corporate and sovereign entities in developed and emerging markets. The performance of investment funds is often highly variable and they are subject to shortfalls that can cause 'runs' (i.e. pervasive and accelerating large-scale investment withdrawals by fund investors). These can generate prolonged system-wide market declines if, for example, the inability to liquidate assets produces liquidity contractions and price-impact elsewhere in the financial system. As described by Hau and Lai (2013) systemic events can emerge from fundamental shocks in particular sub-sectors of the asset universe and then be propagated to other assets as a result of ownership linkages. Such events affect the real economy through the underpricing of the indirectly affected stocks. Hau and Lai show that stock underpricing induced by fund ownership linkages substantially reduced firm-level investment and employment in the affected equities during the 2007/08 crisis. In this context the Financial Stability Board (FSB) has recently highlighted the issue of "liquidity mismatch between fund investments and redemption terms and conditions for fund units" as a significant source of systemic vulnerability. ${ }^{2}$ Likewise, since 2009, the IMF has broadened the remit of country-level Financial Sector Assessment Programmes (FSAPs) to include the non-bank financial sector and this has placed increased monitoring burdens on regulators.

There is therefore a need to develop efficient methods to identify fund attributes associated with exposure to widespread shortfalls. This would help regulators to target their surveillance and perhaps control risks more effectively. Using a recently compiled database from a large sample of investment funds domiciled and reporting in Ireland, we address: (i) the measurement of tail risk within the funds industry as a whole and its components, (ii) the identification of systemically important fund sectors - where these are defined according to the significance of their contribution to the expected shortfall of the entire industry, (iii) an identification of fund characteristics responsible for variation in fund sensitivity to pervasive tail events and (iv), an assessment of whether systemic tail risk attracts a risk premium.

Ireland has the third largest share of Europe's investment fund industry (measured by total assets). This amounts to roughly $17 \%$ of investment fund activity at the end of 2015 (see, ECB statistics, December 2015). The cross-sectional dimension of our sample exceeds 3,000 funds at all times and it spans a variety of market conditions between 2007 and 2015. To our knowledge, our database contains, in greater detail than ever, a more significant proportion of the global funds industry than has previously been analysed in this way. We focus on funds categorised into six types as follows; Equity, Bond, Mixed, Hedge, Real Estate and Other. ${ }^{3}$ In each sector, we consider variation in behaviour/sensitivities according to size-ranked groupings (where size is based on the fund net asset value (NAV)).

\footnotetext{
${ }^{2}$ See the FSBs "Proposed Policy Recommendations to Address Structural Vulnerabilities from Asset Management Activities" (2016).

${ }^{3}$ These are funds investing in mainly equities, mainly bonds, a mixture of equities and bonds, hedged investment strategies, real estate investments and all other types of funds not captured in the former groupings.
} 
To measure sensitivities and contributions to industry-wide tail events we adopt methods that have recently been used in a banking industry context (see for example, Acharya et al. (2010, 2016), Brownlees and Engle (2012, 2016) and Idier et al. (2014)). Acharya et al. (2010) measure systemic risk in financial firms using a systemic expected shortfall (SES) measure. This measure represents the expected amount by which a financial firm will be under-capitalised when the overall financial system is undercapitalised. SES is an increasing function of a firm's marginal expected shortfall and its leverage. They find that SES is able to identify systemically important emerging risks in the banking sector - identifying similar vulnerabilities to those found by stress tests performed at the peak of the financial crisis.

Building on the work of Acharya et al. (2010), Brownlees and Engle (2012) propose a time-varying systemic risk measure, SRISK, that is a function of marginal expected shortfall (MES) and leverage. SRISK is the expected capital loss of a firm conditional on a substantial decline in the market. The SRISK index is used to rank and identify systemically important financial institutions and these are monitored in real-time on the VLAB website at NYU. The MES methodology has three main components. The first is identification of a time varying probability of a market performance below a specified value-at-risk threshold. The second is concerned with the measurement of "expected shortfall" for each fund or fund sector given the probability of a large decline in the overall market (where the distribution of fund-specific returns has a fitted distribution estimated by kernel smoothing methods). The third component concerns the normal time varying sensitivity of fund-specific non-tail performance with respect to that of the market as a whole (where this is achieved by application of dynamic conditional correlation measures using DCC-GARCH modelling).

Our application closely follows the methodology of Brownlees and Engle (2012) but their analysis was in a banking context and some change in emphasis is needed to make it applicable to investment funds. Their measure combines MES and leverage to holistically represent systemic risk. In the case of investment funds leverage is only a significant feature for a small sub-category of leveraged funds (these tend to have high leverage). We therefore focus on the MES part of the SRISK measure and we examine leverage as a determinant of MES. More generally, we assess the behaviours and characteristics that can explain the cross-sectional variation in MES under different circumstances. This adds to the assessment of whether MES is useful (or fit-for-purpose) as is done for banks in the work of Idier et al. (2014) where differences in accounting variables are assessed as explanations for variation in systemic exposure.

Marginal expected shortfall is one of several systemic risk measures that have been proposed since the financial crisis. Adrian and Brunnermeier $(2011,2016)$ propose an alternative measure, denoted $\Delta \mathrm{Co}-\mathrm{VaR}$, and defined as the change in the value-at-risk of the financial system conditional on an individual institution being under distress relative to its median state. So this measure is centered on the impact of stressed firms on the system. On the other hand, MES looks at the impact of the stressed system on the firm. Funds have in the past been the source of systemic risk (e.g. LTCM) but the main focus of our analysis is the impact of systemic tail risk on funds and fund sectors rather than $\triangle \mathrm{Co}-\mathrm{VaR}$, and with this objective the MES approach is more suitable. An issue of endogeneity/simultaneity naturally emerges in this type of analysis and this has been discussed by Acharya et al. (2012) who consider this issue in terms of the question, "are firms weak because of the crisis, or does the crisis happen because firms 
are weak?" They argue that both sub-clauses are potentially true and that it is not possible to infer causality in one direction or the other. We maintain a similar position to that of Acharya et al. and do not try to untangle the simultaneity issue. We therefore focus on measuring the marginal sensitivity of fund-specific performance, or of fund sector performance, to widespread shortfalls in the entire fund industry as represented by our sample.

Our analysis throws light on issues addressed in the IMF's Global Financial Stability Report (2015) that focuses on financial stability in "plain vanilla" funds such as mutual funds and ETFs. The report discusses the presence of incentive problems between investors and portfolio managers and how increased herding amongst managers is making them similarly susceptible to certain types of shocks. Size is therefore not necessarily the most important driver of systemic risk and the IMF report draws attention to investment focus as possibly more influential for tail risk exposure. Another area highlighted in the IMF Report concerns the problem of weak constraints on redemption options that can magnify 'run risks'. Our analysis considers the effects of the magnitude of redemptions on exposure to tail risk and this could help inform the discussion surrounding the design of redemption regulation. It is worthwhile noting that, for the case of money market funds (MMFs), regulation of controls on redemptions (such as liquidity fees and redemption gates) are in the process of being adopted in the US and EU. ${ }^{4}$ There has also been interest in how other types of funds use these kind of controls in crisis moments (e.g. the case of real-estate funds following the Brexit vote in the UK). ${ }^{5}$

Overall, our analysis suggests that there is wide variation in the sensitivity of different fund types to both normal market risk and to extreme negative market events. We find that fund leverage is important in identifying sensitivity to general forms of systemic risk. But our results also reveal that, controlling for normal risk sensitivities, open-endedness, size of redemptions, level of cash holdings and extent of derivative usage are significant determinants of systemic risk measured by MES. We make another important original contribution concerning whether conditional systemic tail risk exposure is rewarded with a risk premium. Using a panel regressing approach that includes beta as a determinant of NAV return we show that MES often contributes a statistically significant additional premium to returns.

The remainder of this paper is organised as follows. Section 2 provides a description of the dynamic MES methodology. Section 3 details our unique investment fund dataset. Section 4 discusses the results of the fund MES, volatility and correlation estimations. Panel regressions designed to identify fund risk characteristics that explain MES exposure are discussed (along with an interpretation of regression results) in Section 5 and concluding remarks are provided in Section 6.

\footnotetext{
${ }^{4}$ See for example "the impacts of SEC adoption of money market fund reforms on shareholder servicing, April 2015, Part 2" and "Detailed Analysis on new UCITS Regulations 2015".

5 "Bank of England was warned about Brexit property fund problems".
} 


\section{Methodology}

\subsection{Marginal Expected Shortfall}

Marginal Expected Shortfall is defined as the expected monthly equity loss per euro invested in a fund taking into account the likelihood that the entire fund sample (market) experiences a tail event. The full-sample return is our proxy for the market return used in Brownlees and Engle (2012) and we will usually use the term "market return" for this proxy (in the next section we discuss the correlation between this proxy and a relevant asset market index). For the purposes of our analysis a tail event is defined as a market loss that exceeds the $5 \%$ value-at-risk (VaR). ${ }^{6}$ The full-sample $5 \%$ VaR is estimated to be a loss of 5.06\% (July 2007 to December 2015). ${ }^{7}$

Following Brownlees and Engle (2012), fund-specific and full-sample returns are modelled as a bivariate process as follows;

$$
\begin{aligned}
& r_{m t}=\sigma_{m t} \epsilon_{m t} \\
& r_{i t}=\sigma_{i t} \rho_{i t} \epsilon_{m t}+\sigma_{i t} \sqrt{1-\rho_{i t}^{2}} \xi_{i t} \\
& \left(\epsilon_{m t}, \xi_{i t}\right) \sim F
\end{aligned}
$$

In (1) the return on the market $r_{m t}$ at time $t$ is a unit-variance random shock $\epsilon_{m t}$ scaled by the conditional volatility of the market $\sigma_{m t}$. Fund returns $r_{i t}$ are driven by both a systematic and idiosyncratic component. The systematic component is a function of the market shock $\epsilon_{m t}$ and the correlation that fund $i$ has with the market, $\rho_{i t}$, scaled by the fund volatility $\sigma_{i t}$. The remaining movement in the return is driven by the idiosyncratic component, the fund specific shock $\xi_{i t}$ and fund volatility.

Market and fund shocks $\left(\epsilon_{m t}, \xi_{i t}\right)$ are assumed to be uncorrelated but not necessarily independent. They are jointly distributed according to the non-parametric distribution F. Although they are assumed to be time independent and uncorrelated, market and fund shocks have tail dependence which is captured by a conditional kernel measure. It is this tail dependence (in combination with the asymmetric time varying conditional variance and correlation) that distinguishes MES from more traditional models involving time-varying systemic risk based solely on beta. The presence of extreme tail dependence is notoriously difficult to test for given that tail events are so infrequently observed. But if tail dependence is present, an alternative to measuring the actual tail dependence is to examine the expected tail dependence given distributional characteristics that are separately measured. The kernel approach discussed below is a way to measure expected tail dependence by combining estimated tail conditional densities (using kernel smoothing) with the probability of a market tail event at each date (which is itself based on corresponding market events, an assumed distribution for such events and a measure of conditional variance/covariance).

More formally, MES is a function of the fund volatility, its correlation with the market and tail expectations representing the standardised market and fund returns conditional on a market tail event. Let the expected value of the standardised market return

\footnotetext{
${ }^{6} 5 \%$ is a commonly used cut off however this can be changed without loss of generality and with minimal effects on our findings.

${ }^{7}$ For comparison: During the period January 2003 to July 2007 this was 2.34\%.
} 
in the tail be $E_{t-1}\left(\epsilon_{m t} \mid \epsilon_{m t}<C / \sigma_{m t}\right)$ and the conditional expected fund-return be denoted $E_{t-1}\left(\xi_{i t} \mid \epsilon_{m t}<C / \sigma_{m t}\right)$ where $\mathrm{C}$ is set to the market non-parametric $5 \%$ VaR. MES is then measured as;

$$
\begin{aligned}
M E S_{i t-1}(C) & =E_{t-1}\left(r_{i t} \mid r_{m t}<C\right) \\
& =\sigma_{i t} E_{t-1}\left(\rho_{i t} \epsilon_{m t}+\sqrt{1-\rho_{i t}^{2}} \xi_{i t} \mid \epsilon_{m t}<C / \sigma_{m t}\right) \\
& =\sigma_{i t} \rho_{i t} E_{t-1}\left(\epsilon_{m t} \mid \epsilon_{m t}<C / \sigma_{m t}\right)+ \\
& \sigma_{i t} \sqrt{1-\rho_{i t}^{2}} E_{t-1}\left(\xi_{i t} \mid \epsilon_{m t}<C / \sigma_{m t}\right)
\end{aligned}
$$

Using Silverman's "rule of thumb" method to determine a bandwidth $h$ (see Silverman (1986)), and following Scaillet (2005) we then measure the conditional tail expectations as:

$$
E_{t-1}\left(\epsilon_{m t} \mid \epsilon_{m t}<C / \sigma_{m t}\right)=\frac{\sum_{t=1}^{T} \epsilon_{m t} \Phi\left(\frac{c-\epsilon_{m t}}{h}\right)}{\sum_{t=1}^{T} \Phi\left(\frac{c-\epsilon_{m t}}{h}\right)} ; \quad E_{t-1}\left(\xi_{i t} \mid \epsilon_{m t}<C / \sigma_{m t}\right)=\frac{\sum_{t=1}^{T} \xi_{i t} \Phi\left(\frac{c-\epsilon_{m t}}{h}\right)}{\sum_{t=1}^{T} \Phi\left(\frac{c-\epsilon_{m t}}{h}\right)}
$$

where $\Phi$ denotes the cumulative normal density.

\subsection{Volatility and Correlation Regression Specification}

Practically, the estimation of MES also requires conditional volatility and correlation. These are estimated using an asymmetric GJR-GARCH process (see Glosten et al. (1993)) as follows;

$$
\begin{gathered}
\sigma_{i t}^{2}=\omega_{i}+\alpha r_{i t-1}^{2}+\gamma r_{i t-1}^{2} I_{i t-1}+\beta \sigma_{i t-1}^{2} \\
\sigma_{m t}^{2}=\omega_{m}+\alpha r_{m t-1}^{2}+\gamma r_{m t-1}^{2} I_{m t-1}+\beta \sigma_{m t-1}^{2} \\
I_{t-1}:= \begin{cases}0, & \text { if } r_{t-1} \geq 0 \\
1, & \text { if } r_{t-1}<0\end{cases}
\end{gathered}
$$

This specification allows for both a leptokurtic distribution in the returns and common volatility characteristics such as volatility clustering. The asymmetry captures a leverage effect commonly observed in asset markets where negative returns increase volatility more than positive returns.

The correlation between the volatility-adjusted returns is modelled as time varying using a Dynamic Conditional Correlation (DCC) specification by Engle $(2002,2009)$ as follows (where $\epsilon_{i t}=r_{i t} / \sigma_{i t}$ and $\epsilon_{m t}=r_{m t} / \sigma_{m t}$ );

$$
\begin{gathered}
\operatorname{Cor}\left(\begin{array}{c}
\epsilon_{i t} \\
\epsilon_{m t}
\end{array}\right)=R_{t}=\left[\begin{array}{cc}
1 & \rho_{i t} \\
\rho_{i t} & 1
\end{array}\right] \\
R_{t}=\operatorname{diag}\left(Q_{i t}\right)^{-1 / 2} Q_{i t} \operatorname{diag}\left(Q_{i} t\right)^{-1 / 2} \\
Q_{i t}=\left(1-\alpha_{C}-\beta_{C}\right) S_{i}+\alpha_{C}\left[\begin{array}{c}
\epsilon_{i t-1} \\
\epsilon_{m t-1}
\end{array}\right]\left[\begin{array}{c}
\epsilon_{i t-1} \\
\epsilon_{m t-1}
\end{array}\right]^{\prime}+\beta_{C} Q_{i t-1}
\end{gathered}
$$


Where $S$ is the unconditional correlation matrix of the firm and market adjusted returns. As discussed by Engle $(2002,2009)$ an important feature of this specification is that the autoregressive parameters are restricted so that the expected long-run correlation is equal to unconditional correlation.

\section{Data}

Our analysis focuses on the large investment fund industry domiciled and reporting in Ireland. The Central Bank of Ireland, Statistics Division collects this dataset through monthly and quarterly investment fund returns. Information on a total of 8125 funds is included as part of this study and the cross sectional sample remains above 3,000 throughout the period studied (in the panel analysis we focus on a smaller subset involving roughly 1,200 funds). The resulting dataset is an unbalanced panel. All entities that are classified as investment funds are included and these are categorised as; Equity, Bond, Mixed, Hedge, Real Estate and Other. A monthly data sample from July 2007 to December 2015 includes investment fund net asset value (NAV) as well as new investor subscriptions and redemptions. The dataset is enriched with the quarterly balance sheet information from March 2008 to December 2015. Our analysis may suffer from a slight survivorship bias since funds that disappear early may be predominantly those that suffer extreme negative returns and stop reporting before the extreme event is recorded. This implies that our results can be regarded as a lower bound on the possible true exposure of fund sectors to pervasive extreme events. Much of the extant literature on fund performance relies on surveys or voluntary disclosures by funds and these studies suffer from a sample selection bias due to the fact that badly performing funds are less likely to volunteer information. Sample selection bias is unlikely to be a problem in our case as all funds are required by regulation to report.

Table 1 provides descriptive statistics for each of the six fund sectors where the categorisation by fund type is based on how funds themselves report their type. The financial crisis occurs near the beginning of the sample. Since the crisis was such a structural event we provide statistics for the crisis and post-crisis periods separately. The negative effect of the crisis is evident from the mean and 10, 50 and 90 percentile values of the returns distribution across all fund types. Unsurprisingly there was also a significant increase in the standard deviation of returns at this time. The HerfindahlHirschman index (HHI) for each fund category is also reported in the descriptive statistics. This measures concentration within the sectors (i.e. how evenly the combined NAV is distributed across the funds in the segment). The low level of the HHI indexes suggest that most sectors are not highly concentrated but market concentration has increased over time since the onset of the crisis. Pre-crisis, the Real Estate fund category was relatively highly concentrated and, although concentration has decreased, this is still the most concentrated of the sectors.

The NAV is equal to the total value of funds' issued shares (or units) and reflects the value of the fund at month end. For our purposes, the investment fund return is defined as the percentage change in NAV after adjusting for net subscriptions (i.e. flows in and out). ${ }^{8}$ The market index is constructed as a NAV weighted index of all

\footnotetext{
${ }^{8}$ The return is estimated assuming flows are added at the start and at the end of the month respec-
} 
investment funds within the sample each month. ${ }^{9}$ Sector performance measured in the same NAV weighted way is shown in Figure 1 since July 2007. Despite the huge losses that many of the funds experienced all fund sectors, excluding the Real Estate sector, have substantially increased in value since the crisis. The Hedge and Bond fund categories have made the biggest financial gains since the lowest point of the crisis and have also grown the most in size over the period.

It is important to stress that our measure of systemic risk is based on the distribution and dynamics of NAV returns from our entire funds sample. This allows us to measure components of the full sample behaviour. A drawback is that the full sample return may not be a good proxy for the true systemic riskiness to which funds are exposed. However, most of our fund sample is focused on European investments and our proxy for systemic risk has a correlation of 0.791 with the EuroStoxx(600) index (the correlation for a subset of extreme movements is even higher). With this level of correlation we believe that our analysis captures most of the interesting systemic dynamics.

\section{$4 \quad$ MES by Sector and Size Groupings}

We firstly apply the Engle and Brownlees MES methodology to NAV-based returns of fund sectors, size groupings within fund sectors and to individual fund returns. The fund-specific MES results are used later as inputs into a panel analysis to assess which fund attributes explain the panel variation in individual fund MES. Since it is not practical to discuss individual fund-level results, we consider how MES and its components behave when they are derived at a sectoral level (and for size groupings within sectors).

\subsection{Tails of Distributions of Sector-Level Returns}

Figure 2 plots the non-parametric fitted distributions of the NAV returns for fund sector portfolios along with the industry-wide distribution. The highly leptokurtic distribution of the Bond funds can be seen reflecting the predominance of relatively small positive and negative returns. The equity fund distribution is acutely positively skewed with fat positive and negative tails.

Figure 3 shows the impact of removing each of two important sectors has on the overall market distribution. Removing the Equity fund sector results in a significant reduction in the size of the left hand tail of the distribution and this reveals the scale of the large negative returns and high volatility experienced by Equity funds over the sample. Removing the Bond fund sector has the opposite effect and adds to the tail

tively. An average of the two resulting investment returns is used in our analysis. This is equivalent to assuming that inflows occur uniformly throughout the month.

9 To construct the index, each fund is assigned a weight based on the fund NAV at the beginning of the month divided by the total sample NAV. This weighting is then multiplied by the funds monthly return. Summing across all funds provides the market return for that month. This process is repeated for each month in the sample. Sector index portfolios are also created using the same method. 
providing evidence of the diversification effects that Bond funds have provided since the crisis.

\subsection{Sector-Level MES \& MES Components}

The evolution of the fund sector conditional return volatility throughout the sample period is shown in Figure 4a. Large spikes in volatility are evident during the crisis period across all fund sectors, with Equity funds exhibiting the highest level of volatility both during and after the crisis. Real Estate funds are also highly volatile exhibiting sudden spikes in volatility that may reflect the illiquidity of their assets. The conditional correlation of fund sector performances with the market performance is shown in Figure 4b. All sectors are highly correlated with the market. Equity and Mixed funds are the most correlated with the market while Real Estate and Others are the least. The Bond fund category has slowly become more correlated with both the market and the Equity fund sector and these positive correlations peak towards the end of the sample. A possible explanation for this is the Asset Purchase Programme (APP) conducted by the ECB/ESCB towards the end of our sample. Such purchases will have raised both bond and equity prices through portfolio rebalancing effects and increased the correlation in their returns.

Figure 5 shows the MES plotted for each sector. This represents the expected loss in the next month conditional on the fund industry experiencing a negative tail event. During 2008 the MES of the Equity fund sector was equal to $16 \%$ of the sector NAV value. The Equity fund MES increased significantly again during 2011 coinciding with the sovereign bond crisis. The Bond fund MES is relatively low in comparison to other sectors but it has increased significantly since late 2011 (it has approximately doubled from around 1.5\% in November 2011 to over 3\% in September 2015).

The dynamic correlation of fund performance with industry-wide performance is a significant component of MES variation and it is also very similar in its behaviour to the more traditional 'beta' measure of risk. We therefore construct a time-varying beta from the correlation and volatility measures and compare this with the MES to see whether MES (i.e. the addition of tail risk dependence) is really adding anything beyond what beta already captures. The conditional time varying beta (based on the DCC-GJR-GARCH analysis) is plotted in Figure 6a. This shows that Equity funds are consistently riskier than the market. All other fund types are less risky than (or equally as risky as) Equity funds measured by beta.

\subsection{MES \& MES Components for Sub-Sectoral Groupings by Size}

To get a better understanding of size effects we divided fund sectors into size-based portfolios and estimate MES and MES components for each of the resulting categories. Specifically, we display various results for 65 within-sector size-based portfolios (i.e. quintiles in the case the Real Estate category and deciles for other six fund categories). All portfolios are weighted in a similar manner to the market index. The 65 portfolios are rebalanced each month to ensure that they are consistent with the size rankings of funds for the same month. We provide visual graphics of the sector/size based 
portfolios in terms of their volatilities, market correlations and betas, as well as their tail risk exposures (MES) in Figures $6 \mathrm{~b}$ to 9. Size groupings are represented as dots with areas that represent the size rankings (the larger the dot the larger are the funds in the associated fund group).

Figure $6 \mathrm{~b}$ shows graphically for each sector and size grouping the relation between systematic risk, as measured by fund beta, and systemic risk, measured by fund MES. A strong linear relationship is present between the two measures of risk reflecting the extent to which MES incorporates traditional beta. Nevertheless, this graph also shows that there are some fund sectors where MES is higher than might be expected based on beta. We can see several size groupings of the Real Estate and Other fund sectors that have significantly higher MES than what might be expected based purely on their beta. This points to the presence of useful additional information in MES over and above what is captured by beta.

From an investors perspective, expected fund returns should be commensurate with expected fund systemic risk exposures. Some indication of this ex ante tradeoff can be gleaned from the ex post relationship and this can be decomposed into components. Figures 7 to 9 show the cross-sectional relationship between average NAV return (ex post) and each of the main risk measures: volatility, correlation and MES for the crisis and post-crisis sample respectively. Figure 7 reveals significantly lower volatilities in the post-crisis period across all fund sector and size categories. During the crisis nearly all fund portfolios experienced negative average returns (this ex post relation does not look like the kind of trade-off investors would have perceived ex ante). The Equity fund sector, which is the most volatile, experienced the greatest losses during the market crash. This is unsurprising given its high correlation with the market. In the post-crisis sample there is evidence of a more normal positive relationship between return and risk along the frontier (this perhaps reflects increased investor awareness/recognition of such risks after the crisis and it gives possibly a truer measure of the ex ante compensation for risk). Interestingly, there are multiple funds that under-perform for their level of volatility (i.e. they have returns well below the return-volatility frontier).

Figure 9 plots the MES systemic risk measure against fund average return. Again, funds with the highest systemic tail riskiness had the greatest average losses during the crisis. Post-crisis the MES has decreased for all sectors and there is a perceptible (almost) linear frontier trade-off appearing between risk and return as might be expected. The MES for the Equity fund sector drops from an average loss in the tail of $10 \%$ to under $6 \%$. A linear frontier relationship is evident between the best performing deciles in the Bond, mixed and Equity funds. A large fraction of the Real Estate and Other fund groupings under-perform relative to the frontier. A number of Hedge funds out-perform the frontier that can be drawn between the best performing Bond and Equity funds deciles.

The effect of fund size is difficult to ascertain from the above graphical analysis. In Figure 9 the size deciles for each fund sector are represented by dots of increasing area with size. If one excludes the 'Real-Estate' and 'Other' categories, there is a clear sector-based clustering of size-based observations while sectors can easily be distinguished from each other. This indicates that sector matters more than fund size. There is some hint of a positive relation between size and MES for the Equity category but 
the evidence is far from strong at this stage.

\subsection{Sector Risk Relative to Sector Size}

Banulescu and Dumitrescu (2015) propose using a size based weighting method to identify the most systemically risky institutions in the system. They call this measure the component expected shortfall (CES). We follow their methodology in calculating risk shares as follows;

$$
C E S_{i t}(C)=-w_{i t}\left[\sigma_{i t} \rho_{i t} E_{t-1}\left(\epsilon_{m t} \mid \epsilon_{m t}<C / \sigma_{m t}\right)+\sigma_{i t} \sqrt{1-\rho_{i t}^{2}} E_{t-1}\left(\xi_{i t} \mid \epsilon_{m t}<C / \sigma_{m t}\right)\right]
$$

Table 2 shows the CES statistic representing the percentage of system risk that each portfolio contributes on average. The size of the portfolio, $w_{i t}$, is also provided as a percentage of the whole system on average. Focusing on only the largest portfolios for each sector, it can be seen that the largest $10 \%$ of Equity funds account for $24 \%$ of the total NAV on average. However, they account for a disproportionate $39 \%$ of industrywide risk. In contrast, the largest $10 \%$ of the Bond funds account on average for $18 \%$ of the total industry size in our sample but only $11 \%$ of the system-wide risk. Similarly, apart from one outlier, the contribution to systemic risk is less than the contribution to the size of the overall system in the cases of Hedge, Real Estate and Other fund categories. Mixed funds, like Equity funds contribute more on average than their size would suggest.

We can also see from Table 2 that the MES contributions relative to the size contributions tend to be positively related to size. For example, the Equity contribution to industry-wide MES is typically around $150 \%$ of the equity contribution to industrywide NAV but this trends from $135 \%$ to $155 \%$ across the size deciles. There are similar upward trends (although slight) by size categories for the Bond, Mixed and Hedge sectors. While this size effect is perceptible it is not conclusive given that size is also related to other fund characteristics. The regression analysis in the following section allows additional controls for characteristics that may be correlated with both size and MES.

\section{Panel Regression Analysis: MES \& Fund Attributes}

We now turn to an analysis of the (time and cross-sectional) panel variation in sensitivity to systemic tail risk. For this analysis we make use of the individual fund-specific MES estimates (rather than just the MES of fund categories or size deciles) and we employ fund characteristics derived from investment fund balance sheet variables, income statement information and other fund characteristics. We removed funds with less than 25 quarterly observations since once the sample size declines below this level fund-specific conditional variance, correlation and MES measurements start to become less efficient. We focus our regression analysis on funds that report in the three most popular reporting currencies. We consider all fund sectors except Real Estate funds (in 
this sector the updating of valuation was slow and the number of funds small). Applying these criteria we provide regression analysis for a sub-sample of the total population for which MES was calculated - consisting of roughly 1,200 funds and 50,690 individual observations. The sample period for this part of our analysis extends from Q1 2009 to Q4 2015. ${ }^{10}$ To cater for the fact that funds differ according to their reporting currency we apply our regression analysis separately to groups reporting in Euros, US dollars and Pounds Sterling respectively. All asset values are converted to Euros before NAV calculations. The separate regressions for each reporting currency (with different time fixed effects) therefore allows for different currency effects. In addition we include in each regression a variable to capture the proportion of a fund's assets that are denominated in currencies other than the reporting currency.

We estimate the following panel regression using a random effects specification in which the residual is permitted to be autoregressive of order 1 (estimation is done in Stata V14 using a Generalised Least Squares approach);

$$
\begin{aligned}
& \text { MES } S_{i t}=\beta_{1} \text { Size }_{i t}+\beta_{2} \text { Size }_{i t}^{2} \\
& +\beta_{3} \text { Foreign }_{i t}+\beta_{4} \text { Expense }_{i t}+\beta_{3} \text { Leverage }_{i t-1} \\
& +\beta_{5} \text { Turnover }_{i t-1}+\beta_{6} \text { Derivative }_{i t-1}+\beta_{7} \text { Redeem }_{i t-1}+\beta_{8} \text { Issue }_{i t-1} \\
& +\beta_{9} \text { Cash }_{i t-1}+\beta_{10} \text { Beta }_{i t-1}+\beta_{11} \text { Open }_{i t}+\beta_{12} \text { Retail }_{i t} \\
& +u_{i}+\epsilon_{i t}-\theta \epsilon_{i t-1}
\end{aligned}
$$

where, the dependent variable is MES exposure stated in percentage points for each investment fund $i$ and for quarter $t$, while the explanatory variables for $i$ and $t$, (or $i$ and $t-1$ ), are respectively; Size in euro billions (based on NAV), Size $e^{2}$, value of holdings relative to NAV of assets issued in currencies other than the reporting currency of the fund (Foreign), the expense ratio (Expense) relative to total assets, fund leverage (Leverage) as a proportion of NAV, the average of sales and purchases of securities relative to NAV (Turnover), the average of sales and purchases of derivatives relative to NAV (Derivative), investor withdrawals relative to beginning of period NAV (Redeem), investment inflows relative to beginning of period NAV (Issue), the fund NAV-return beta with respect to fund industry NAV return (beta), cash holdings relative to NAV (Cash), an openness dummy and a Retail-Fund dummy. The beta variable is included to control for systematic risk so as to identify what is attributable to tail risk as distinct from systematic risk. We include fixed-effects (coefficients not reported) for time but individual fund random effects $u_{i}$ remain.

Summary statistics for the regression variables (including the 'within' and 'between' standard deviations) for each of the three main reporting currency groupings and the fund sectors is provided in Table 3. This reveals a good mix of within and between variation among the explanatory variables. It should be said at the outset that we have a preference for an empirical model that would reveal how MES exposure varies in a cross-sectional sense. Our prior is that funds differ from each other more than they vary individually through time. While this may not be consistently true for each of the explanatory variables individually (as described in Table 3) we nevertheless assume that fund differences - taken jointly - are the dominant explanation for

\footnotetext{
10 As a robustness check we conducted the same analysis including the crisis period (i.e. over the period from Q1 2008 to Q4 2015). The primary results of the analysis do not differ significantly in these two alternative samples. The additional results are available from the authors on request.
} 
variation in the exposure to pervasive tail risk. Taking this viewpoint we avoid a fully dynamic specification that would introduce the need for instrumenting and a Generalised Methods of Moments approach that would require dropping of observed fixed effects (i.e. openness, retail) and that could lead to weak and inconclusive results.

While a fully dynamic specification is not employed we must accept that our dependent variable (arising from an estimated time series model) possesses within-fund dynamics. These dynamics give rise to significant autoregression in the residuals when a standard panel regression approach is used. To improve the efficiency of estimates we employ a GLS random effects estimation strategy that allows for AR(1) residuals. In addition, where there is a concern of possible simultaneity issues we use lagged values of the intended explanatory variables. Finally, observed cross-sectional effects are controlled for by the use of dummy variables (e.g. for fund openness and retail investor focus).

The above model is applied to each fund sector according to the reporting currency (we limit attention to three currencies, Euro, USD and GBP) but in our discussion of results below we focus almost entirely on the Equity fund sector (a small number of significant parameters found for other sectors are briefly discussed for completeness). We did not find many statistically significant results for the other sectors and this is perhaps not surprising given our discussion of Figure 5 where we observe the dominance of MES variation within the Equity fund sector. There was a significant change in the reporting template used by funds making returns to the Central bank of Ireland from Q1 2014 (with more information requested and more granular identification of the categories within which assets are grouped). We therefore present regression results for the sample covering this last 8 quarters in addition to the full sample results. We do not find many large differences in the results and this probably reflects the fact that any systematic differences in the variables across the two samples are captured by the time fixed-effects.

Before discussing regression results it is worth noting from descriptive statistics in Table 3 that there is significant correlation between the proposed explanatory variables in Equation 8 and that MES is directly correlated with these variables (we only display the correlations for the case of Equity funds reporting in EUR). The pooled correlations shown in the top panel of Table 3 reveal that MES has a positive correlation with leverage, turnover, derivative usage, redemption and issuance rates. Negative correlations exist between MES and fund size, the foreign proportion of a fund portfolio, the expense ratio and the cash component of a fund's assets. Unsurprisingly, beta is highly correlated with MES. But these raw correlations are difficult to interpret - specifically we do not know whether they reflect common time or cross-sectional variation. It would also be important to control for other potentially confounding factors. Nevertheless, the broad conclusions that can be drawn from the raw correlations is consistent with priors.

Table 3 also permits an assessment of the multicollinearity issues in our proposed regression variables. Issue and redemption rates are highly correlated (with a correlation coefficient of 0.90 ). These two variables are then also quite highly correlated with leverage ( 0.62 and 0.65 respectively), with turnover $(0.49$ and 0.55 respectively) and with derivative usage (0.39 and 0.36 respectively). Size is highly correlated with $S i z e^{2}$. While these collinearities could cause the estimated parameters to vary widely 
depending on which variables are included, we found that most coefficients were relatively insensitive to the omission of closely correlated variables. This may reflect the role of the included time fixed-effects.

The remainder of Table 3 contains statistics on the between, within and overall variability of each of the regression variables. For funds reporting in EUR there is more between variation in MES than within variation. Explanatory variables that are also dominated by between variation include the size and foreign variables. Otherwise, it is within variation that tends to dominate. This is generally the case for the expense ratio, leverage, the turnover rate, the redemption rate and the cash proportion. While these statistics are helpful in understanding which variables are most likely to explain MES variation they are limited by their unitary dimensionality. To obtain more reliable insights we turn now to an assessment of panel regression results.

\subsection{MES Panel Regression Results: Equity Funds}

Table 4 provides results for the regression in equation 8 pertaining to the Equity sector categorised according to reporting currencies (EUR, USD and GBP) and to the full and post-2013 samples respectively. These regressions include the lagged conditional beta as a control variable facilitating an analysis of the relationship between fund characteristics and MES that is not already accounted for by the more standard beta risk metric. If particular explanatory variables are merely weak proxies for beta, rather than explaining tail risk sensitivity, they should become insignificant once beta is included in the MES regression (since beta is strongly related to MES its inclusion will have effects on the other parameters of the regression similar to those achieved by a Heckman (1976) correction). This is particularly important for variables such as the holdings of foreign assets and units in other funds since these are indicative of normal risk reduction through diversification as well as extreme risk exposure through network connectedness.

In general, the results of the MES regressions in Table 4 have intuitive appeal and their interpretation coincides broadly with extant literature. For all of the regressions we observe that in excess of $60 \%$ of the overall variation in MES is explained by the regression. Coefficients are generally signed as expected and there is a high degree of statistical significance of most coefficients. Coefficients also generally retain their significance in the post-2013 sub-sample regression. The goodness of fit can be traced in the first instance to time fixed effects (this is apparent from the additional panel$R^{2}$ statistics provided in the Table that pertain to supplementary regressions in which the time fixed-effects were held constant). The first of the supplementary regressions includes just the leverage variable. This reveals that leverage alone can often account for a significant proportion of the MES variation (this is especially true for the EUR reporting Equity funds where the within $R^{2}$ is $13.7 \%$ and $18.5 \%$ for the full and post2013 sub-sample respectively). In this case it is valid to conclude that leverage is both statistically significant and economically relevant. Leverage however, does not account for much variation in MES for the case of Equity funds reporting in either USD or GBP.

The second supplementary regression includes the time varying beta constructed using the dynamic correlations and variances estimated in the first part of our study. 
Once beta is included the panel- $R^{2}$ statistics rise dramatically. In the case of GBP reporting Equity funds the $R^{2}$ with just leverage and beta is essentially equal to the $R^{2}$ achieved by the comprehensive regression specification. So in this case we cannot conclude that the additional variables from the full specification make a meaningful contribution to the variation in exposure to pervasive tail risk. For the EUR reporting funds there remains between $5 \%$ and $10 \%$ of a difference in $R^{2}$ between the specification that includes all variables and the specification with just leverage and beta. A slightly larger gap exists for the USD reporting funds. In these cases it seems that the additional variables matter significantly in both a statistical and economic sense.

Turning to an assessment of the significance of parameters it is clear that many are statistically significant and have intuitively correct signs. We first consider whether fund size explains MES. We included both Size and Size $e^{2}$ to allow for possible nonlinearity in this relation. There is evidence of a negative Size effect for Equity funds reporting in USD and the significance of the Size $e^{2}$ coefficient implies that this negative effect weakens as size reaches its extreme. Elsewhere there is limited evidence of a significant size effect. IMF research indicates that size is not necessarily a harbinger of vulnerability to systemic risk and our generally weak results on this variable seem to support this view.

Holdings of foreign assets is often regarded as a measure of connectedness and this would be consistent with an increased exposure to tail risk. However, foreign asset holdings may also reflect more diversification. The diversification effect should be mitigated by the inclusion of beta in the MES regression. On balance we would expect a positive effect from holdings of foreign assets (especially since systemic events tend to be international in nature). We find that most coefficients on the Foreign variable are statistically significantly positive.

We note that the estimated coefficient on the Expense ratio is only statistically significant in one case and in this case it has a negative sign. A positive relation between fees and risk would be consistent with the findings by Golec (1992). High fund expenses, of which fees are a large part, have been shown to result in increased risk taking behaviour. Ackermann et al. (1999) find a significant relationship between management fees and risk-taking behaviour measured by the ex post volatility of returns. This suggests that management fees can create an agency problem. Overall however, our results suggest that this effect is insignificant and not likely to be specifically associated with tail risk exposure.

The coefficient on Leverage is significantly positive at the $1 \%$ level of significance in the case of EUR reporting Equity funds (and for the combined sample of funds where currency fixed-effects are included). Leverage is also positive and highly statistically significant for USD and GBP reporting funds over the full sample but not for the post-2013 sub-sample. This suggests that leverage effects are statistically important in explaining exposure to pervasive tail events. However, we see from the mean and standard deviation statistics that (excluding the Real Estate fund sector) leverage is in fact very low on average and has a relatively high level of dispersion. Further analysis of this variable - not reported - reveals that it is right skewed. It is in fact the case that a small number of funds have relatively high leverage and also have high exposure to pervasive shortfalls. This effect is strong enough to dominate the full sample results but we acknowledge that the leverage issue is not as pervasive as it might first 
appear.

Turnover is indicative of excessive churn in a portfolio and it may also reflect run risk activity in the midst of a crisis. Where the coefficient is statistically significant it is positive and indicative of increased exposure to systemic tail risk. This coefficient had increased magnitude and significance when beta was excluded as a control. It is therefore mostly associated with normal risk exposure captured by beta. Use of risk hedging is represented by the Derivative variable - which is in fact a measure of the amount of use made of derivatives by a fund without regard to its buyer or seller designation. For funds reporting in any of the three currencies, and for those reporting in EUR, the coefficient on derivative usage is highly statistically significant and negative for both temporal samples. This reduced exposure to pervasive tail risk arguably reflects the buying of protection against very large adverse events. Selling of protection for a small return is likely to be a feature of derivative usage for some funds but this is not apparent from the derivative activity variable we employ. More analysis would therefore be required to be confident about our interpretation. There is a distinct absence of statistical significance of the coefficient on derivative usage for the funds reporting in USD and GBP and this is an interesting difference worthy of future analysis.

The coefficient on the Redeem variable is highly statistically significant and positive for the combined sample and for funds reporting in EUR. Higher redemption rates may reflect relatively loose redemption policy at the fund level which would tend to exacerbate run-risks. The redemption effect is consistent with views expressed by the FSB on the liquidity transformation provided by some funds. There is little evidence that the redemption effect is counteracted by an issuance effect (all coefficients on the Issue variable are insignificant except for the case of funds reporting in GBP). In this case the Issue variable is more highly correlated with the Redeem variable and when it is excluded from the regression the Redeem coefficient becomes significant. In general it seems safe to conclude that relatively high redemption rates are ubiquitously associated with more exposure to systemic tail risk.

Holdings of liquid assets (Cash) has significantly negative coefficients in the case of the combined sample, for USD reporting funds and for EUR reporting funds in the post-2013 sample (elsewhere it is generally positive but insignificant). This suggests that cash provides significant protection from pervasive tail events but it is not yet clear how this operates. It seems unlikely that the mitigating effects of Cash for MES exposure operates through the postponement of sales when there is an extreme negative systemic shock. This smoothing of sales could help in avoidance of losses during temporary troughs, but for more pervasive extreme events delaying sales is unlikely to result in less exposure to truely systemic shortfalls. It seems more likely to us that relatively high Cash buffers is reflective of a cautious investment strategy more generally (i.e. funds with larger cash balances may possess relatively more cash-like assets which are inherently more stable during extreme negative systemic events). We leave further exploration of this for future work.

Fund openness and retail investor focus are both dummy variables with positive and significant coefficients. Openness would naturally expose funds to investment outflows during extreme negative events so this result is intuitive. The higher systemic tail risk exposure for funds that cater to the retail investor is more difficult to under- 
stand. This could be due to reduced monitoring of fund managers by unprofessional investors allowing them to assume more difficult to understand tail risk exposures. It may also reflect the flightiness of retail investment flows in extreme circumstances. We leave exploration of these conjectures for future analysis.

\subsection{MES Panel Regression Results: Non-Equity Funds}

We provide regression results for all other fund sectors (except Real Estate funds) in Table 5. In this case we report results only for the funds that report in either EUR or USD. There are generally far fewer statistically significant coefficients to discuss for these regressions since MES is neither high nor variable in these cases (which follows from our earlier reflections on Figure 5 and Table 3). In the case of Mixed funds there is a significant negative Size effect which eventually is outweighed by a positive Size $e^{2}$ effect. It is interesting that Leverage is insignificant in all but one small-sample case when it has a negative coefficient. For EUR reporting funds in the Bond sector the coefficient on the Derivative variable is negative and highly significant which confirms what was found for the Equity funds. Also for the EUR reporting Bond funds the redemption and issuance rates have significant effects of opposite sign and this is intuitively appealing. Issuance activity also significantly mitigates systemic tail risk exposure for Other funds reporting in USD. The signs and significance of coefficients on Cash, Openness and Retail variables tell a very inconsistent story. For the cases of Mixed funds and Hedge funds there is a statistically significant elevation in exposure to MES for funds catering to the Retail investor. This is consistent with our findings for the Equity sector.

\subsection{NAV Panel Regression Results: Equity Funds}

One could argue that systemic risk exposure is acceptable if it is sufficiently compensated for by increased expected return. Fund attributes that lead to higher MES exposure could be exactly the same characteristics that lead to improved returns. Improved returns could be appearing in two ways. One is through an improved risk premium. Another is through improved alpha. To assess whether either of these attributes feature as compensation for MES exposure, we use the return on NAV (adjusted for redemptions and issues) as the dependent variable in almost the same regression specification as was used for the MES analysis above. The NAV return regressions differ in one important respect from the MES regressions in that MES (lagged) itself is included as an explanatory variable in the NAV regressions. The results for the Equity funds are provided in Table 6 following the same structure as was used for Table 4. As in the MES analysis the first pair of regressions involves funds regardless of their reporting currency over two different temporal samples (as before, we include reporting currency fixed-effects). The other three regression pairs relate to funds reporting in EUR, USD and GP respectively.

The Panel- $\bar{R}^{2}$ goodness-of-fit statistics are all in excess of $55 \%$ for the inclusive regression specification but we can see from the between and within $R^{2}$ statistics that much of this explained variation is attributable to time fixed-effects. Goodness-of-fit statistics are also provided for the cases where Leverage alone and Leverage combined with 
beta and MES are included in the regression (in these cases we have held the time fixed effects constant at their full model levels). These $R^{2}$ statistics give a better indication of what is explained by regression variables beyond the time fixed-effects. It is immediately apparent that Leverage alone explains almost no NAV Return variation (any variation explained is of the between type and even this is less than $2 \%$ ). MES and beta however are more significant contributors to goodness-of-fit. For the full temporal sample about $5 \%$ of variation in NAV is attributable to the MES and beta variation but this can be traced mostly to within variation.

Despite the small amount of explanatory power in the NAV regressions it is noteworthy that many individual parameters are statistically significant so it is possible to identify the sign of the effects attributable to fund characteristics and balance sheet items. Our expectation is that statistically significant parameters in the NAV regression will tend to be the same sign as their corresponding parameters in the MES regressions (exposure to risk requiring a risk premium). With some minor exceptions this does not seems to be the case in general. For example, the parameters on Size and Size ${ }^{2}$, where significant, tend to be opposite in sign to the same parameters in Table 4.

The effect of fund size on fund performance is commonly debated in extant literature. Several banking studies find a positive relationship between size and systemic risk measures (see Laeven et al. (2014) for a discussion). The results in Table 6 indicate that larger funds tend to have higher returns until this is outweighed by the (smaller in magnitude) negative parameter on the $S i z e^{2}$ variable (which is mostly opposite to the case for the corresponding MES regression). In general though there is a dearth of statistically significant coefficients on the Size variables so the size issue remains somewhat inconclusive.

Coefficients on the Foreign exposure always had a positive coefficient in the MES regressions but in more than half of the significant cases it is negative in the returns regressions (the results for the full sample regression involving funds reporting in EUR are an exception). The coefficient on the Expense variable is generally negative and significant in the NAV regression indicating that funds charging high fees often deliver lower returns. In this case there is no strong evidence in the MES regression that high Expense funds also expose investors to more tail risk. The case of EUR reporting Equity funds is a case where investors obtain significantly more protection from pervasive tail risk (with a significant negative parameter in the MES regression) and significantly higher returns (with a significant positive parameter in the returns regression).

As already mentioned there is evidence from the MES regression that Leverage generates more exposure to pervasive tail risk for a small number of funds. There are only three statistically significant coefficients on Leverage in the NAV regression and all of these are positive implying that the higher tail risk exposure from leverage is often rewarded with a risk premium.

For the case of Turnover there is very little common significance in the parameters of the corresponding MES and Return regressions. In nearly all comparisons across the MES and Return regressions the signs of Turnover parameters differ so this does not support the case for a risk premium for tail risk exposure arising through the Turnover channel. Derivative usage was associated with significant protection against pervasive tail risks in the MES regression and investors do not appear to suffer smaller returns 
for this protection except in the case of the post-2013 sub-sample. While Redemptions were associated with increased tail risk exposure there is no consistent evidence that this leads to a significant risk premium in the NAV regression. Issuance did not significantly explain tail risk exposure in the MS regression but it is significantly positive for returns in the case of Equity funds reporting in GBP. Cash was associated with lower tail risk exposure in the MES analysis but it is mostly not a significant determinant of returns (only in the case of EUR reporting Equity funds is Cash associated with relatively more negative returns as might be expected for more risk averse investment strategies).

Beta and MES should both be positive contributors to returns since they are both ex ante variables for systematic and systemic risk exposures respectively. We obtain positive and significant parameters for the full temporal sample in the case of MES but a negative parameter for the post-2013 sample where significant. Beta does not always appear to be positive and significant when it is included along with MES. Since MES and beta are highly correlated the inclusion of both variables does not always give the desired result. We can report however that when only one or other of these risk measures is included in the NAV regression it usually turns out to be positive and significant.

Finally, the coefficients on the Openness and Retail dummy variables in the NAV regression usually have the opposite sign to those in the corresponding MES regressions. This implies that the open and retail-focused funds expose their investors to relatively more systemic tail risk while delivering relatively lower returns. We conducted NAV regressions for the other fund sectors but the results are not sufficiently significant to add new or interesting insights beyond what has been discussed for the Equity sector (these results are available from the authors on request).

\section{Conclusion}

A Marginal Expected Shortfall (MES) approach is used to measure the sensitivity of fund performance to pervasive tail-risk (where 'performance' is based on NAV-return adjusting for changes in the size of the investment due to net-subscriptions to the fund). The aim of the analysis is to identify funds, fund categories and fund attributes that are particularly associated with, or explain, MES. Thus, we examine the dynamics of MES and its components (using time series and kernel estimation techniques) and we examine the relationship between MES and investment fund characteristics using a random effects panel technique controlling for normal risk due to beta. We also assess whether there is a performance-related explanation for MES sensitivities.

From our volatility modeling, we find that risks vary significantly depending on the investment focus of a fund. Over the entire sample period, Equity funds contribute disproportionately to MES risk. Equity funds also have the most volatile overall performances and they have a high level of correlation with the rest of the market. While descriptive statistics suggest that size and MES are positively correlated this result does not survive a more detailed analysis that includes additional controls. In fact, our panel regression analysis suggests that fund size is seldom significant in explaining variation in MES. In the few cases where size coefficients are statistically significant 
they imply a negative association until a very extreme size is reached.

Open-ended funds and funds catering to Retail investors have relatively higher exposures to pervasive tail risk. Funds with high levels of interconnectedness through holdings of foreign assets were also found to have relatively high levels of exposures to MES. Leverage is statistically significant and (based on its contribution to goodness-offit) an economically important determinant of MES. Despite evidence to the contrary by Ackermann et al. (1999) of a significant positive relationship between management fees and risk-taking behaviour measured by the ex post volatility of returns, our analysis uncovers only occasional statistical significance of the Expense variable. When significant, the effect is usually negative in sign and this therefore does not support earlier findings that 'agency issues' are at play.

Interestingly, post-crisis panel regressions show that funds are consistently compensated for their exposure to tail risk and this is in addition to compensation for exposure to systematic risk represented by 'beta'. Examining the trade-off of MES exposure and return performance shows that there are segments of the fund industry that under-perform for the level of their risk exposures (ex post). This is especially true for the Retail-focused sub-category.

The methods used in this study could, in our view, easily be extended to a forecasting and stress-testing context (through a simulation using parameters from the estimated relation). This would allow identification of individual investment funds that are at particularly high risk of exposure to systemic stability under an array of macroeconomic circumstances. It would also permit a mapping of the interconnectedness of the consequences of systemic shortfalls under different scenarios (this would be similar to how Hau and Lai, 2013, expose the effects of ownership linkages). An assessment of systemic shocks on the pattern of investor flows would also be amenable to a similar analysis. We leave these extensions for future research. 


\section{References}

Acharya, V., R. Engle, and M. Richardson (2012). Capital Shortfall: A new approach to ranking and regulating systemic risks. The American Economic Review 102(3), 59-64.

Acharya, V. V., L. H. Pedersen, T. Philippon, and M. Richardson (2016). Measuring systemic risk. Forthcoming, Review of Financial Studies.

Acharya, V. V., L. H. Pedersen, T. Philippon, and M. P. Richardson (2010). Measuring systemic risk. FRB of Cleveland Working Paper.

Ackermann, C., R. McEnally, and D. Ravenscraft (1999). The performance of hedge funds: Risk, return, and incentives. The Journal of Finance 54(3), 833-874.

Adrian, T. and M. K. Brunnermeier (2011). CoVaR. Technical report, National Bureau of Economic Research.

Adrian, T. and M. K. Brunnermeier (2016). CoVaR. American Economic Review 106(7), 1705-1741.

Banulescu, G.-D. and E.-I. Dumitrescu (2015). Which are the SIFIs? A Component Expected Shortfall approach to systemic risk. Journal of Banking E Finance 50, 575588.

Brownlees, C. and R. F. Engle (2016). SRISK: A Conditional Capital Shortfall measure of systemic risk. Forthcoming, Review of Financial Studies.

Brownlees, C. T. and R. Engle (2012). Volatility, correlation and tails for systemic risk measurement. NYU-VLAB Working paper.

Engle, R. (2002). Dynamic Conditional Correlation: A simple class of multivariate generalized autoregressive conditional heteroskedasticity models. Journal of Business $\mathcal{E}$ Economic Statistics 20(3), 339-350.

Engle, R. (2009). Anticipating correlations: A new paradigm for risk management. Princeton University Press.

Financial Stability Board (2016). Proposed policy recommendations to address structural vulnerabilities from asset management activities. Consultative Document (June).

Glosten, L. R., R. Jagannathan, and D. E. Runkle (1993). On the relation between the expected value and the volatility of the nominal excess return on stocks. The Journal of Finance 48(5), 1779-1801.

Golec, J. H. (1992). Empirical tests of a principal-agent model of the investorinvestment advisor relationship. Journal of Financial and Quantitative Analysis 27(01), $81-95$.

Hau, H. and S. Lai (2013). Real effects of stock underpricing. Journal of Financial Economics 108(2), 392-408.

Heckman, J. J. (1976). The common structure of statistical models of truncation, sample selection and limited dependent variables and a simple estimator for such models. In Annals of Economic and Social Measurement, Volume 5, number 4, pp. 475-492. NBER. 
Idier, J., G. Lamé, and J.-S. Mésonnier (2014). How useful is Marginal Expected Shortfall for the measurement of systemic exposure? A practical assessment. Journal of Banking \& Finance 47, 134-146.

IMF (2014). Review of the Financial Sector Assessment Program: Further adaptation to the post crisis era. Technical report.

IMF (2015). The asset management industry and financial stability. Technical report.

Laeven, M. L., L. Ratnovski, and H. Tong (2014). Bank size and systemic risk. Number 14. International Monetary Fund.

Scaillet, O. (2005). Nonparametric estimation of Conditional Expected Shortfall. Insurance and Risk Management Journal 74(1), 639-660.

Silverman, B. W. (1986). Density estimation for statistics and data analysis, Volume 26. CRC press. 
Table 1: Descriptive Statistics \& Concentration Indices: NAV return and NAV proportions

\begin{tabular}{lcccccccc}
\hline & Mean & 10th \% & median & 90th \% & std dev & HII & Start NAV & End NAV \\
\hline (2007-2009) & & & & & & & & \\
Equity & -0.0144 & -0.1072 & -0.0094 & 0.0752 & 0.0838 & 0.0051 & 234.4609 & 166.7691 \\
Bond & -0.0019 & -0.0421 & 0.0010 & 0.0419 & 0.0615 & 0.0098 & 113.2341 & 111.0707 \\
Mixed & -0.0094 & -0.0764 & -0.0042 & 0.0498 & 0.0772 & 0.0490 & 53.0319 & 38.4184 \\
Hedge & -0.0054 & -0.0737 & -0.0003 & 0.0592 & 0.0888 & 0.0124 & 37.9792 & 30.3015 \\
RealEstate & -0.0227 & -0.0979 & -0.0003 & 0.0442 & 0.1037 & 0.1347 & 5.0579 & 2.7804 \\
Other & -0.0066 & -0.0613 & 0.0000 & 0.0426 & 0.0746 & 0.0736 & 125.9015 & 74.3775 \\
& & & & & & & & \\
(2009-2015) & & & & & & & & \\
Equity & 0.0074 & -0.0445 & 0.0095 & 0.0571 & 0.0513 & 0.0052 & 166.7691 & 541.9699 \\
Bond & 0.0042 & -0.0267 & 0.0028 & 0.0352 & 0.0344 & 0.0114 & 111.0707 & 456.2910 \\
Mixed & 0.0051 & -0.0347 & 0.0050 & 0.0447 & 0.0526 & 0.0255 & 38.4184 & 170.8117 \\
Hedge & 0.0055 & -0.0394 & 0.0034 & 0.0545 & 0.0582 & 0.0086 & 30.3015 & 149.8201 \\
RealEstate & 0.0054 & -0.0307 & 0.0000 & 0.0472 & 0.0949 & 0.1025 & 74.3775 & 58.3688 \\
Other & 0.0017 & -0.0400 & 0.0009 & 0.0447 & 0.0653 & 0.0443 & 74.3775 & 58.3688 \\
\hline
\end{tabular}

This table reports descriptive statistics and concentration measures for fund sectors for 20072009 and 2009-2015. The mean, 10th percentile, median(50th percentile), 90th percentile and standard deviation of monthly NAV is shown in each case. Start NAV is the total net asset value of that sector at the start of the sample period and end NAV is the sector NAV at the end of the sample period. NAV values are in Billions of Euro. HII is the Herfindahl-Hirschman index of concentration measuring the inequality of concentration according to size deciles. 
Table 2: Size and Marginal Expected Shortfall Proportional Contributions

\begin{tabular}{|c|c|c|c|c|c|c|c|c|c|c|c|}
\hline & & Size 1 & Size 2 & Size 3 & Size 4 & Size 5 & Size 6 & Size 7 & Size 8 & Size 9 & Size 10 \\
\hline \multirow[t]{3}{*}{ Equity } & $\%$ Size & 0.0457 & 0.1490 & 0.2969 & 0.5143 & 0.8402 & 1.3391 & 2.1774 & 3.7245 & 6.9130 & 25.8633 \\
\hline & $\%$ MES & 0.0615 & 0.2018 & 0.3991 & 0.7002 & 1.1911 & 1.9092 & 3.2849 & 5.4728 & 10.3001 & 40.1951 \\
\hline & MES/SIZE & 1.35 & 1.35 & 1.34 & 1.36 & 1.42 & 1.43 & 1.51 & 1.47 & 1.49 & 1.55 \\
\hline \multirow[t]{3}{*}{ Bond } & $\%$ Size & 0.0422 & 0.1198 & 0.2307 & 0.4020 & 0.6578 & 1.0675 & 1.7613 & 3.0379 & 5.4024 & 19.8453 \\
\hline & $\%$ MES & 0.0147 & 0.0547 & 0.1079 & 0.1802 & 0.2971 & 0.5136 & 0.8782 & 1.5686 & 2.1793 & 10.8688 \\
\hline & MES/SIZE & 0.35 & 0.46 & 0.47 & 0.45 & 0.45 & 0.48 & 0.5 & 0.52 & 0.4 & 0.55 \\
\hline \multirow[t]{3}{*}{ Mixed } & $\%$ Size & 0.0135 & 0.0448 & 0.0928 & 0.1608 & 0.2583 & 0.3899 & 0.5942 & 0.9596 & 1.7945 & 7.6594 \\
\hline & $\%$ MES & 0.0062 & 0.0409 & 0.0762 & 0.1361 & 0.2404 & 0.3339 & 0.5959 & 0.9829 & 1.6692 & 6.3778 \\
\hline & MES/SIZE & 0.46 & 0.91 & 0.82 & 0.85 & 0.93 & 0.86 & 1 & 1.02 & 0.93 & 0.83 \\
\hline \multirow[t]{3}{*}{ Hedge } & $\%$ Size & 0.0208 & 0.0709 & 0.1314 & 0.2038 & 0.2976 & 0.4224 & 0.6223 & 0.9409 & 1.6236 & 4.9259 \\
\hline & $\%$ MES & 0.0105 & 0.0473 & 0.0974 & 0.1715 & 0.2104 & 0.3049 & 0.4375 & 0.6755 & 1.2127 & 3.6387 \\
\hline & MES/SIZE & 0.5 & 0.67 & 0.74 & 0.84 & 0.71 & 0.72 & 0.7 & 0.72 & 0.75 & 0.74 \\
\hline \multirow[t]{3}{*}{ Real Estate } & \% Size & 0.0049 & 0.0182 & 0.0476 & 0.0957 & 0.3986 & & & & & \\
\hline & $\%$ MES & 0.0055 & 0.0104 & 0.0174 & 0.2307 & 0.2986 & & & & & \\
\hline & MES/SIZE & 1.12 & 0.57 & 0.37 & 2.41 & 0.75 & & & & & \\
\hline \multirow[t]{3}{*}{ Other } & $\%$ Size & 0.0050 & 0.0170 & 0.0331 & 0.0567 & 0.0915 & 0.1512 & 0.2341 & 0.3622 & 0.6578 & 2.1683 \\
\hline & $\%$ MES & 0.0027 & 0.0169 & 0.0233 & 0.0356 & 0.0311 & 0.0987 & 0.1883 & 0.2636 & 0.2950 & 0.8372 \\
\hline & MES/SIZE & 0.54 & 0.99 & 0.7 & 0.63 & 0.34 & 0.65 & 0.8 & 0.73 & 0.45 & 0.39 \\
\hline
\end{tabular}

This table reports the proportional contributions of each sector to both industry size and industry MES. Each portfolio size \% represents the contribution of that portfolio to the total NAV of the system (Sum of all portfolios). The MES \% represents the contribution of that portfolio to the systemic risk of the system. Mean values over the period July 2007-December 2015. Due to low number of Real Estate funds they are sorted into quintiles rather than deciles. 
Table 3: Descriptive Statistics / Correlations of MES Regression Variables

\begin{tabular}{|c|c|c|c|c|c|c|c|c|c|c|c|c|}
\hline & \multicolumn{12}{|c|}{ Variable Correlations for EUR Reporting Equity Funds } \\
\hline & $M E S$ & Size & $S i z e^{2}$ & Foreign & Expense & Leverage & Turnover & Derivative & Redeem & Issue & Cash & Beta \\
\hline Size & -0.047 & 1.000 & & & & & & & & & & \\
\hline$S_{i z e^{2}}$ & -0.007 & 0.861 & 1.000 & & & & & & & & & \\
\hline Foreign & -0.125 & -0.068 & -0.081 & 1.000 & & & & & & & & \\
\hline Expense & -0.147 & -0.045 & -0.042 & 0.141 & 1.000 & & & & & & & \\
\hline Leverage & 0.179 & -0.074 & -0.038 & -0.094 & -0.088 & 1.000 & & & & & & \\
\hline Turnover & 0.171 & -0.081 & -0.039 & -0.006 & -0.034 & 0.447 & 1.000 & & & & & \\
\hline Derivative & 0.057 & -0.043 & -0.023 & -0.078 & -0.053 & 0.253 & 0.176 & 1.000 & & & & \\
\hline Redeem & 0.239 & -0.123 & -0.054 & -0.109 & -0.112 & 0.651 & 0.547 & 0.355 & 1.000 & & & \\
\hline Issue & 0.243 & -0.094 & -0.041 & -0.139 & -0.124 & 0.620 & 0.486 & 0.393 & 0.897 & 1.000 & & \\
\hline Cash & -0.102 & -0.046 & -0.035 & 0.046 & 0.089 & -0.018 & -0.002 & -0.014 & -0.049 & -0.067 & 1.000 & \\
\hline Beta & 0.704 & -0.032 & -0.010 & -0.002 & -0.143 & 0.043 & 0.072 & 0.010 & 0.088 & 0.085 & -0.113 & 1.000 \\
\hline
\end{tabular}

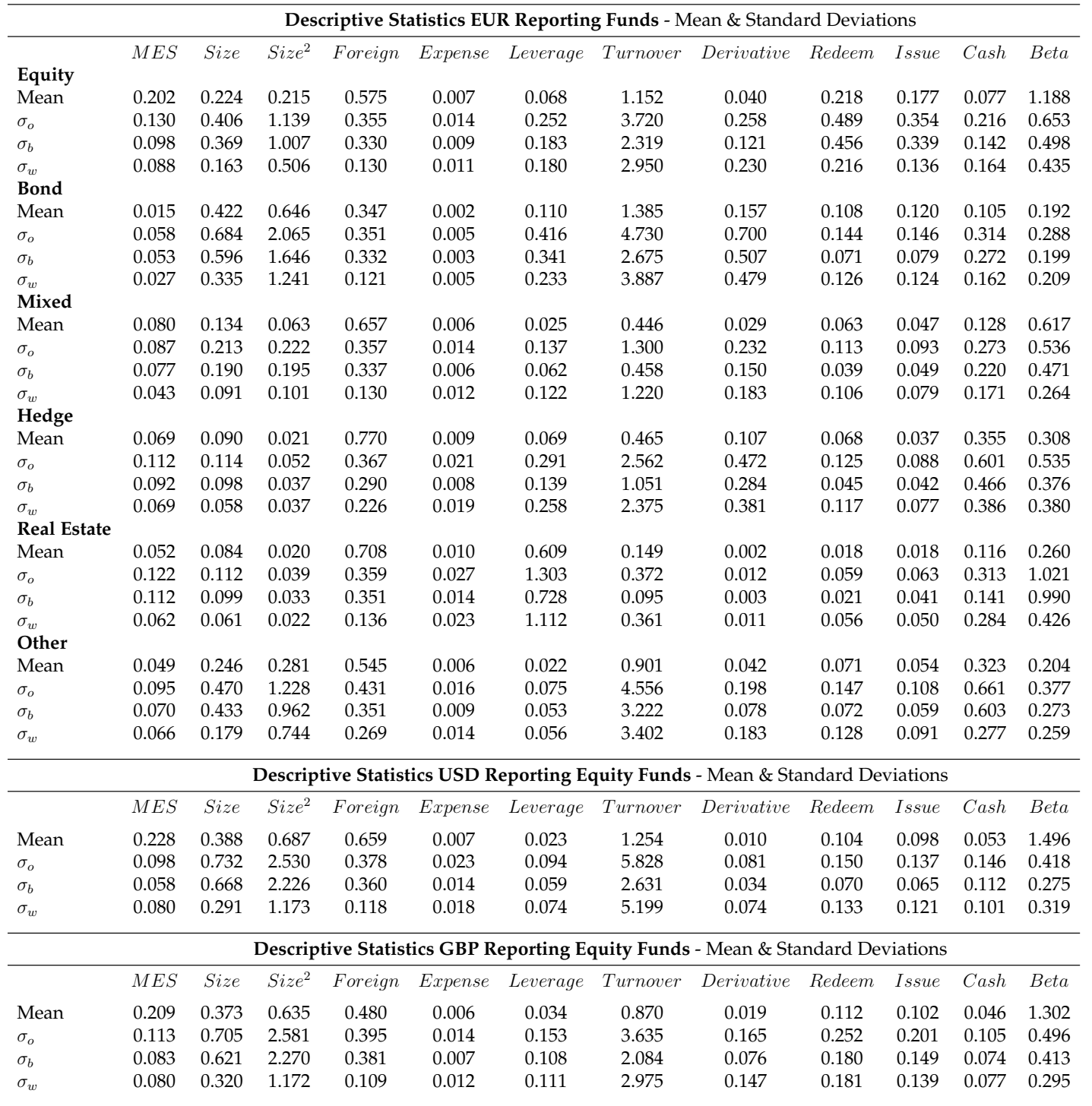

This table reports descriptive statistics and (in the case of Equity funds reporting in Euros) correlations for the variables described in Equation 8 for quarterly observations from Q1 2009 to Q4 2015. The number of observations and number of funds included in each statistic are the same as in the corresponding columns of the MES regression results tables. The standard deviation statistics; $\sigma_{w}, \sigma_{b}$ and $\sigma_{o}$ refer to within, between and overall variation respectively. 
Table 4: Fund Characteristics \& MES: Equity Funds

\begin{tabular}{|c|c|c|c|c|c|c|c|c|}
\hline \multirow[b]{2}{*}{ Sample } & \multicolumn{2}{|c|}{ All } & \multicolumn{2}{|c|}{ Euro } & \multicolumn{2}{|c|}{ USD } & \multicolumn{2}{|c|}{ GBP } \\
\hline & 09Q1:15Q4 & 14Q1:15Q4 & 09Q1:15Q4 & 14Q1:15Q4 & 09Q1:15Q4 & 14Q1:15Q4 & 09Q1:15Q4 & 14Q1:15Q4 \\
\hline $\mathrm{N}$ & 19457 & 5531 & 6640 & 1892 & 10050 & 2867 & 1579 & 444 \\
\hline $\mathrm{n}$ & 715 & 714 & 245 & 245 & 367 & 366 & 59 & 59 \\
\hline \multirow[t]{2}{*}{$\mathrm{Size}_{t}$} & $-0.817^{* *}$ & -0.001 & -0.586 & 0.113 & $-1.035^{* *}$ & -0.158 & 0.415 & -0.918 \\
\hline & 0.030 & 1.000 & 0.500 & 0.920 & 0.020 & 0.790 & 0.700 & 0.500 \\
\hline \multirow[t]{2}{*}{ Size $_{t}^{2}$} & $0.190^{*}$ & 0.005 & 0.384 & 0.165 & $0.199 *$ & 0.029 & -0.049 & 0.137 \\
\hline & 0.060 & 0.980 & 0.170 & 0.660 & 0.080 & 0.850 & 0.870 & 0.710 \\
\hline \multirow[t]{2}{*}{ Foreign $_{t}$} & $1.419^{* * *}$ & $2.518^{* * *}$ & 0.180 & $2.155^{* * *}$ & $2.595^{* * *}$ & $3.617^{* * *}$ & $1.410^{*}$ & 0.191 \\
\hline & 0.000 & 0.000 & 0.730 & 0.010 & 0.000 & 0.000 & 0.080 & 0.840 \\
\hline \multirow[t]{2}{*}{ Expense $_{t}$} & -2.211 & -0.352 & $-11.272^{* *}$ & 10.633 & -0.078 & 1.639 & -4.311 & 1.738 \\
\hline & 0.380 & 0.960 & 0.050 & 0.470 & 0.980 & 0.880 & 0.530 & 0.880 \\
\hline \multirow[t]{2}{*}{ Leverage $_{t-1}$} & $3.031^{* * *}$ & $5.852^{* * *}$ & $2.983^{* * *}$ & $7.822^{* * *}$ & $3.111^{* * *}$ & 0.105 & $2.477^{* * *}$ & 2.341 \\
\hline & 0.000 & 0.000 & 0.000 & 0.000 & 0.000 & 0.920 & 0.010 & 0.160 \\
\hline \multirow[t]{2}{*}{ Turnover $_{t-1}$} & 0.012 & $0.052^{* * *}$ & $0.038^{*}$ & 0.044 & -0.001 & $0.043^{* *}$ & $0.070^{*}$ & -0.194 \\
\hline & 0.180 & 0.000 & 0.090 & 0.250 & 0.950 & 0.020 & 0.090 & 0.260 \\
\hline \multirow[t]{2}{*}{ Derivative $_{t-1}$} & $-1.044^{* * *}$ & $-0.693^{* *}$ & $-1.169^{* * *}$ & $-1.041^{* * *}$ & 0.333 & -0.213 & -0.658 & 0.679 \\
\hline & 0.000 & 0.020 & 0.000 & 0.010 & 0.510 & 0.740 & 0.220 & 0.510 \\
\hline \multirow{2}{*}{ Redeem $_{t-1}$} & $0.957^{* * *}$ & $1.420^{* * *}$ & $0.985^{* * *}$ & 0.398 & $1.240^{* * *}$ & $2.562^{* * *}$ & -0.605 & -1.733 \\
\hline & 0.000 & 0.000 & 0.000 & 0.570 & 0.000 & 0.000 & 0.310 & 0.220 \\
\hline \multirow[t]{2}{*}{ Issue $_{t-1}$} & 0.311 & -0.065 & 0.532 & 1.075 & -0.417 & $-1.328^{*}$ & $2.240^{* * *}$ & $3.391^{* *}$ \\
\hline & 0.230 & 0.900 & 0.260 & 0.280 & 0.210 & 0.070 & 0.000 & 0.030 \\
\hline \multirow[t]{2}{*}{ Cash $_{t-1}$} & $-0.777^{* * *}$ & $-2.204^{* *}$ & -0.174 & $-2.157^{*}$ & $-1.591^{* * *}$ & $-3.419^{* *}$ & 0.130 & -0.747 \\
\hline & 0.010 & 0.020 & 0.710 & 0.100 & 0.000 & 0.040 & 0.920 & 0.800 \\
\hline \multirow[t]{2}{*}{ Beta $_{t-1}$} & $5.208^{* * *}$ & $5.961^{* * *}$ & $5.180^{* * *}$ & $5.389^{* * *}$ & $5.289^{* * *}$ & $7.042^{* * *}$ & $6.613^{* * *}$ & $11.317^{* * *}$ \\
\hline & 0.000 & 0.000 & 0.000 & 0.000 & 0.000 & 0.000 & 0.000 & 0.000 \\
\hline \multirow{2}{*}{ Open } & $10.532^{* * *}$ & $8.830^{* * *}$ & $7.628^{* * *}$ & $8.010^{* * *}$ & $11.909^{* * *}$ & $8.495^{* * *}$ & 3.879 & 1.426 \\
\hline & 0.000 & 0.000 & 0.000 & 0.000 & 0.000 & 0.000 & 0.460 & 0.740 \\
\hline \multirow[t]{2}{*}{ Retail } & $2.131^{* * *}$ & $1.899^{* * *}$ & $4.750^{* * *}$ & $3.343^{* *}$ & 1.139 & $1.092^{*}$ & 2.473 & 2.540 \\
\hline & 0.000 & 0.000 & 0.000 & 0.020 & 0.140 & 0.100 & 0.510 & 0.400 \\
\hline$\rho$ & 0.474 & 0.341 & 0.438 & 0.360 & 0.524 & 0.280 & 0.483 & 0.346 \\
\hline$\sigma_{u}$ & 0.046 & 0.037 & 0.054 & 0.044 & 0.038 & 0.031 & 0.037 & 0.024 \\
\hline \multirow[t]{2}{*}{$\sigma_{\epsilon}$} & 0.043 & 0.039 & 0.049 & 0.045 & 0.037 & 0.034 & 0.036 & 0.034 \\
\hline & \multicolumn{8}{|c|}{ Within, Between and Overall $R^{2}$ all independent variables included in regression } \\
\hline$R_{w}^{2}$ & 0.706 & 0.641 & 0.700 & 0.612 & 0.747 & 0.706 & 0.819 & 0.692 \\
\hline$R_{b}^{2}$ & 0.541 & 0.624 & 0.557 & 0.636 & 0.519 & 0.579 & 0.703 & 0.885 \\
\hline \multirow[t]{2}{*}{$R_{o}^{2}$} & 0.618 & 0.615 & 0.610 & 0.620 & 0.658 & 0.632 & 0.691 & 0.792 \\
\hline & \multicolumn{8}{|c|}{ Within, Between and Overall $R^{2}$ Leverage and time FEs included in regression } \\
\hline$R_{w}^{2}$ & 0.001 & 0.012 & 0.003 & 0.044 & 0.001 & 0.000 & 0.000 & 0.011 \\
\hline$R_{b}^{2}$ & 0.057 & 0.121 & 0.137 & 0.185 & 0.001 & 0.002 & 0.035 & 0.020 \\
\hline$R_{o}^{2}$ & 0.038 & 0.102 & 0.057 & 0.167 & 0.001 & 0.002 & 0.014 & 0.012 \\
\hline & & ithin, Betwee & and Overal & $R^{2}$ Leverage & Beta and ti & FEs inclu & $\mathrm{d}$ in regress & \\
\hline$R_{w}^{2}$ & 0.317 & 0.177 & 0.307 & 0.161 & 0.367 & 0.236 & 0.347 & 0.093 \\
\hline$R_{b}^{2}$ & 0.478 & 0.597 & 0.754 & 0.645 & 0.648 & 0.571 & 0.874 & 0.883 \\
\hline$R_{o}^{2}$ & 0.421 & 0.496 & 0.559 & 0.548 & 0.483 & 0.434 & 0.685 & 0.769 \\
\hline
\end{tabular}

For the Equity fund sector this table reports panel regression results for the case of fund-specific Marginal Expected Shortfall as a function of investment fund characteristics as described in Equation 8. The motivation for the random effects (AR1) regression specification and a description of the explanatory variables is discussed under Equation 8 of this paper. The first two columns of results pertain to All Equity funds regardless of their reporting currency and for two different sample periods (reporting currency fixed effects are included in this case). The remaining pairs of columns pertain to Equity funds reporting in Euro, USD and GBP respectively. Coefficient estimates are scaled by 100 and p-values are provided below coefficients. The level of the significance of coefficients is denoted as follows; ${ }^{*} p<.1,{ }^{* *} p<.05,{ }^{* * *} p<.01$. Table 3 contains descriptive statistics on the regression variables. Time fixed effects are always included but coefficients are not reported for brevity. The number of observations and number of cross-sectional units included in each regression are denoted as $\mathrm{N}$ and $\mathrm{n}$ respectively. The goodness of fit statistics (within, between and overall) are provided for the regression shown and also for regressions containing subsets of the explanatory variable list as described in the sub-headings (for the subset regressions we hold the time fixed-effects and $\rho$ at their full model values). 
Table 5: Fund Characteristics \& MES: Bond, Mixed, Hedge \& Other Funds

\begin{tabular}{|c|c|c|c|c|c|c|c|c|}
\hline \multirow{4}{*}{$\begin{array}{l}\text { Reporting in: } \\
\mathrm{N} \\
\mathrm{n}\end{array}$} & \multicolumn{2}{|c|}{ Bond } & \multicolumn{2}{|c|}{ Mixed } & \multicolumn{2}{|c|}{ Hedge } & \multicolumn{2}{|c|}{ Other } \\
\hline & EUR & USD & EUR & USD & EUR & USD & EUR & USD \\
\hline & 2666 & 4340 & 1989 & 1311 & 987 & 1772 & 620 & 679 \\
\hline & 98 & 159 & 75 & 49 & 37 & 66 & 24 & 25 \\
\hline \multirow[t]{2}{*}{ Size $_{t}$} & -0.555 & -0.330 & $-8.344^{* * *}$ & 0.880 & -18.264 & -0.595 & -4.244 & -4.909 \\
\hline & 0.300 & 0.510 & 0.000 & 0.690 & 0.170 & 0.800 & 0.290 & 0.350 \\
\hline \multirow[t]{2}{*}{$S_{i z e_{t}^{2}}$} & -0.018 & 0.070 & $7.415^{* * *}$ & $-1.362^{*}$ & 10.452 & -0.238 & 0.878 & 0.574 \\
\hline & 0.900 & 0.550 & 0.000 & 0.080 & 0.620 & 0.850 & 0.480 & 0.910 \\
\hline \multirow[t]{2}{*}{ Foreign $_{t}$} & 0.567 & $-0.677^{*}$ & $-1.113^{* *}$ & 0.511 & -0.631 & 0.625 & -1.225 & 0.537 \\
\hline & 0.170 & 0.060 & 0.040 & 0.430 & 0.460 & 0.290 & 0.170 & 0.420 \\
\hline \multirow[t]{2}{*}{ Expense $_{t}$} & -8.741 & $-6.666^{*}$ & 4.820 & $-14.319^{* *}$ & -3.924 & $-11.407^{*}$ & -1.891 & 1.379 \\
\hline & 0.350 & 0.060 & 0.300 & 0.020 & 0.560 & 0.080 & 0.880 & 0.840 \\
\hline \multirow[t]{2}{*}{ Leverage $_{t-1}$} & 0.200 & 0.164 & 0.068 & 0.377 & 0.239 & 0.115 & -2.674 & $-1.772^{* * *}$ \\
\hline & 0.420 & 0.310 & 0.880 & 0.290 & 0.640 & 0.880 & 0.520 & 0.000 \\
\hline \multirow[t]{2}{*}{ Turnover $_{t-1}$} & 0.010 & 0.003 & -0.031 & $0.122^{* *}$ & 0.009 & -0.007 & 0.071 & -0.003 \\
\hline & 0.450 & 0.660 & 0.540 & 0.030 & 0.860 & 0.770 & 0.400 & 0.950 \\
\hline \multirow[t]{2}{*}{ Derivative $_{t-1}$} & $-0.476^{* * *}$ & -0.059 & 0.341 & -0.230 & -0.355 & -0.186 & 0.072 & 0.082 \\
\hline & 0.000 & 0.490 & 0.340 & 0.410 & 0.510 & 0.340 & 0.950 & 0.870 \\
\hline \multirow[t]{2}{*}{ Redeem $_{t-1}$} & $0.772^{* *}$ & -0.202 & 0.554 & -0.703 & 0.636 & -1.208 & 1.099 & -0.729 \\
\hline & 0.020 & 0.430 & 0.280 & 0.370 & 0.600 & 0.160 & 0.380 & 0.310 \\
\hline \multirow[t]{2}{*}{ Issue $_{t-1}$} & $-0.738^{* *}$ & 0.123 & -0.374 & -0.644 & 1.508 & 0.500 & -2.131 & $-3.295^{* * *}$ \\
\hline & 0.040 & 0.670 & 0.620 & 0.500 & 0.430 & 0.640 & 0.240 & 0.010 \\
\hline \multirow[t]{2}{*}{$\operatorname{Cash}_{t-1}$} & $0.647^{*}$ & -0.515 & -0.074 & 0.092 & -0.069 & $0.822^{*}$ & $-1.954^{* *}$ & 0.161 \\
\hline & 0.080 & 0.250 & 0.880 & 0.830 & 0.910 & 0.070 & 0.040 & 0.850 \\
\hline \multirow[t]{2}{*}{ Beta $_{t-1}$} & 0.228 & $4.040^{* * *}$ & $3.108^{* * *}$ & $1.311^{* * *}$ & $-1.388^{* * *}$ & 0.088 & $3.132^{* * *}$ & 0.347 \\
\hline & 0.310 & 0.000 & 0.000 & 0.000 & 0.000 & 0.720 & 0.000 & 0.350 \\
\hline \multirow[t]{2}{*}{ Open } & $-38.559^{* * *}$ & $0.000^{* * *}$ & $-10.023^{* *}$ & 0.425 & $0.000^{* * *}$ & $5.775^{* * *}$ & $6.960^{*}$ & 3.773 \\
\hline & 0.000 & 0.000 & 0.030 & 0.950 & 0.000 & 0.010 & 0.080 & 0.270 \\
\hline \multirow[t]{2}{*}{ Retail } & $-2.206^{*}$ & -0.564 & $7.512^{* * *}$ & $8.023^{* * *}$ & $9.977^{* *}$ & 1.924 & -4.394 & $6.148^{* *}$ \\
\hline & 0.080 & 0.580 & 0.000 & 0.000 & 0.030 & 0.400 & 0.140 & 0.050 \\
\hline$\rho$ & 0.546 & 0.708 & 0.693 & 0.594 & 0.767 & 0.521 & 0.729 & 0.718 \\
\hline$\sigma_{u}$ & 0.028 & 0.039 & 0.044 & 0.062 & 0.087 & 0.055 & 0.056 & 0.056 \\
\hline$\sigma_{\epsilon}$ & 0.023 & 0.024 & 0.027 & 0.036 & 0.046 & 0.042 & 0.041 & 0.030 \\
\hline
\end{tabular}

\begin{tabular}{lcccccccc} 
& \multicolumn{6}{c}{ Within, Between and Overall $R^{2}$ all independent variables included in regression } \\
$R_{w}^{2}$ & 0.123 & 0.440 & 0.453 & 0.337 & 0.095 & 0.153 & 0.330 & 0.187 \\
$R_{b}^{2}$ & 0.601 & 0.631 & 0.498 & 0.282 & 0.059 & 0.086 & 0.290 & 0.187 \\
$R_{o}^{2}$ & 0.474 & 0.452 & 0.484 & 0.294 & 0.078 & 0.111 & 0.343 & 0.186
\end{tabular}

For the Bond, Mixed, Hedge and Other fund sectors this table reports panel regression results for the case of fund-specific Marginal Expected Shortfall as a function of investment fund characteristics as described in Equation 8. The motivation for the random effects (AR1) regression specification and a description of the explanatory variables is discussed under Equation 8 of this paper. The pairs of columns pertain to each of the 4 fund sectors reporting in Euro and USD respectively. Coefficient estimates are scaled by 100 and p-values are provided below coefficients. The level of the significance of coefficients is denoted as follows; ${ }^{*} p<.1{ }^{* *} p<.05,{ }^{* * *} p<.01$. Table 3 contains descriptive statistics on the regression variables. Time fixed effects are always included but coefficients are not reported for brevity. The number of observations and number of cross-sectional units included in each regression are denoted as $\mathrm{N}$ and $\mathrm{n}$ respectively. The goodness of fit statistics (within, between and overall) are provided below the main regression results. 
Table 6: Fund Characteristics \& NAV Return: Equity Funds

\begin{tabular}{|c|c|c|c|c|c|c|c|c|}
\hline \multirow{4}{*}{$\begin{array}{l}\text { Sample } \\
\mathrm{N} \\
\mathrm{n}\end{array}$} & \multicolumn{2}{|c|}{ All } & \multicolumn{2}{|c|}{ Euro } & \multicolumn{2}{|c|}{ USD } & \multicolumn{2}{|c|}{ GBP } \\
\hline & 09Q1:15Q4 & 14Q1:15Q4 & 09Q1:15Q4 & 14Q1:15Q4 & 09Q1:15Q4 & 14Q1:15Q4 & 09Q1:15Q4 & 14Q1:15Q4 \\
\hline & 19382 & 5513 & 6564 & 1870 & 10049 & 2869 & 1581 & 446 \\
\hline & 715 & 714 & 245 & 245 & 367 & 366 & 59 & 59 \\
\hline \multirow[t]{2}{*}{$\mathrm{Size}_{t}$} & $0.576^{* * *}$ & $1.062^{* * *}$ & 0.294 & $0.953^{*}$ & $0.590^{* *}$ & $1.245^{* * *}$ & -0.036 & -0.261 \\
\hline & 0.010 & 0.000 & 0.550 & 0.090 & 0.020 & 0.000 & 0.950 & 0.730 \\
\hline \multirow[t]{2}{*}{ Size $_{t}^{2}$} & $-0.151^{* *}$ & $-0.261^{* * *}$ & -0.121 & -0.300 & $-0.131^{*}$ & $-0.286^{* * *}$ & -0.040 & 0.031 \\
\hline & 0.020 & 0.000 & 0.480 & 0.110 & 0.070 & 0.010 & 0.810 & 0.880 \\
\hline \multirow[t]{2}{*}{ Foreign $_{t}$} & $-0.655^{* * *}$ & $-0.915^{* * *}$ & $0.847^{* * *}$ & 0.517 & $-1.730^{* * *}$ & $-2.110^{* * *}$ & 0.276 & $1.044^{*}$ \\
\hline & 0.000 & 0.000 & 0.010 & 0.230 & 0.000 & 0.000 & 0.480 & 0.060 \\
\hline \multirow[t]{2}{*}{ Expense $_{t}$} & $-4.348^{*}$ & $-28.962^{* * *}$ & $13.345^{*}$ & $-24.531^{* *}$ & $-6.396^{* *}$ & 1.103 & $-62.448^{* * *}$ & $-73.504^{* * *}$ \\
\hline & 0.090 & 0.000 & 0.070 & 0.050 & 0.020 & 0.930 & 0.000 & 0.000 \\
\hline \multirow[t]{2}{*}{ Leverage $_{t-1}$} & 0.511 & $1.264^{* * *}$ & $0.817^{*}$ & $1.560^{* *}$ & 0.319 & 1.088 & -0.902 & -0.404 \\
\hline & 0.130 & 0.010 & 0.060 & 0.040 & 0.640 & 0.240 & 0.360 & 0.750 \\
\hline \multirow{2}{*}{ Turnover $_{t-1}$} & $-0.047^{* * *}$ & -0.001 & $-0.063^{* *}$ & -0.010 & $-0.033^{* * *}$ & -0.025 & $-0.068^{*}$ & 0.078 \\
\hline & 0.000 & 0.980 & 0.020 & 0.810 & 0.000 & 0.320 & 0.080 & 0.600 \\
\hline \multirow[t]{2}{*}{ Derivative $_{t-1}$} & -0.053 & $-0.769^{*}$ & 0.322 & -0.212 & -0.031 & -0.280 & 0.639 & -1.540 \\
\hline & 0.850 & 0.070 & 0.320 & 0.690 & 0.970 & 0.740 & 0.420 & 0.240 \\
\hline \multirow[t]{2}{*}{ Redeem $m_{t-1}$} & -0.281 & $0.829^{*}$ & $-0.696^{*}$ & -0.654 & 0.432 & 0.571 & $-3.127^{* * *}$ & -1.881 \\
\hline & 0.270 & 0.090 & 0.080 & 0.390 & 0.310 & 0.450 & 0.000 & 0.190 \\
\hline \multirow{2}{*}{ Issue $_{t-1}$} & -0.086 & $-1.177^{*}$ & -0.012 & 0.249 & -0.463 & -1.127 & $3.936^{* * *}$ & $4.170^{* *}$ \\
\hline & 0.790 & 0.070 & 0.980 & 0.820 & 0.320 & 0.220 & 0.000 & 0.020 \\
\hline \multirow[t]{2}{*}{ Cash $_{t-1}$} & -0.321 & 0.693 & $-0.678^{*}$ & -0.257 & -0.439 & 1.732 & -1.075 & 0.787 \\
\hline & 0.270 & 0.450 & 0.100 & 0.830 & 0.320 & 0.290 & 0.410 & 0.770 \\
\hline \multirow[t]{2}{*}{$B e t a_{t-1}$} & $-0.715^{* * *}$ & $1.340^{* * *}$ & $-1.403^{* * *}$ & $0.853^{*}$ & 0.191 & $2.557^{* * *}$ & 0.666 & $3.394^{* * *}$ \\
\hline & 0.000 & 0.000 & 0.000 & 0.060 & 0.410 & 0.000 & 0.240 & 0.000 \\
\hline \multirow[t]{2}{*}{$M E S_{t-1}$} & $13.946^{* * *}$ & $-3.248^{*}$ & $16.703^{* * *}$ & 0.353 & $11.858^{* * *}$ & $-5.921^{* *}$ & $8.574^{* * *}$ & $-14.065^{* *}$ \\
\hline & 0.000 & 0.070 & 0.000 & 0.900 & 0.000 & 0.030 & 0.000 & 0.020 \\
\hline \multirow[t]{2}{*}{ Open } & $-2.657^{* * *}$ & $-3.676^{* * *}$ & $-2.215^{* * *}$ & $-3.541^{* * *}$ & $-2.002^{* * *}$ & $-2.424^{* * *}$ & -1.915 & -1.380 \\
\hline & 0.000 & 0.000 & 0.000 & 0.000 & 0.000 & 0.010 & 0.250 & 0.520 \\
\hline \multirow[t]{2}{*}{ Retail } & $-0.389^{*}$ & -0.214 & -0.812 & $-1.281^{* *}$ & $-0.474^{* *}$ & -0.593 & 0.015 & -0.527 \\
\hline & 0.070 & 0.480 & 0.120 & 0.040 & 0.050 & 0.130 & 0.990 & 0.730 \\
\hline$\rho$ & 0.063 & 0.039 & 0.063 & 0.070 & 0.091 & -0.025 & -0.032 & 0.035 \\
\hline$\sigma_{u}$ & 0.008 & 0.007 & 0.012 & 0.000 & 0.005 & 0.009 & 0.006 & 0.000 \\
\hline \multirow[t]{2}{*}{$\sigma_{\epsilon}$} & 0.059 & 0.052 & 0.060 & 0.055 & 0.055 & 0.048 & 0.046 & 0.039 \\
\hline & \multicolumn{8}{|c|}{ Within, Between and Overall $R^{2}$ all independent variables included in regression } \\
\hline$R_{w}^{2}$ & 0.585 & 0.674 & 0.590 & 0.624 & 0.635 & 0.740 & 0.669 & 0.704 \\
\hline$R_{b}^{2}$ & 0.066 & 0.135 & 0.055 & 0.193 & 0.111 & 0.202 & 0.459 & 0.253 \\
\hline$R_{o}^{2}$ & 0.568 & 0.639 & 0.567 & 0.595 & 0.623 & 0.706 & 0.661 & 0.679 \\
\hline & & Within, Betw & een and Ove & $11 R^{2}$ Lever & ge and time & Es included & in regression & \\
\hline$R_{w}^{2}$ & 0.000 & 0.003 & 0.000 & 0.006 & 0.000 & 0.000 & 0.001 & 0.001 \\
\hline$R_{b}^{2}$ & 0.019 & 0.018 & 0.001 & 0.004 & 0.010 & 0.003 & 0.003 & 0.017 \\
\hline$R_{o}^{2}$ & 0.002 & 0.005 & 0.000 & 0.003 & 0.000 & 0.001 & 0.000 & 0.002 \\
\hline & With & in, Between a & nd Overall $R$ & Leverage, B & ta, MES and & time FEs incl & uded in regre & ssion \\
\hline$R_{w}^{2}$ & 0.063 & 0.003 & 0.077 & 0.010 & 0.063 & 0.004 & 0.054 & 0.049 \\
\hline$R_{b}^{2}$ & 0.015 & 0.023 & 0.002 & 0.001 & 0.001 & 0.064 & 0.254 & 0.023 \\
\hline$R_{o}^{2}$ & 0.051 & 0.009 & 0.056 & 0.003 & 0.046 & 0.017 & 0.066 & 0.039 \\
\hline
\end{tabular}

For the Equity fund sector this table reports panel regression results for the case of fund-specific NAV-Return as a function of the same investment fund characteristics as described in Equation 8 with the addition of MES itself. The motivation for the random effects (AR1) regression specification and a description of the explanatory variables is discussed under Equation 8 of this paper. The first two columns of results pertain to All Equity funds regardless of their reporting currency and for two different sample periods (reporting currency fixed effects are included in this case). The remaining pairs of columns pertain to Equity funds reporting in Euro, USD and GBP respectively. Coefficient estimates are scaled by 100 and $p$-values are provided below coefficients. The level of the significance of coefficients is denoted as follows; ${ }^{*} p<.1$, ${ }^{* *} p<.05,{ }^{* * *} p<.01$. Time fixed effects are always included but coefficients are not reported for brevity. The number of observations and number of cross-sectional units included in each regression are denoted as $\mathrm{N}$ and $\mathrm{n}$ respectively. The goodness of fit statistics (within, between and overall) are provided for the regression shown and also for regressions containing subsets of the explanatory variable list as described in the sub-headings (for the subset regressions we hold the time fixed-effects and $\rho$ at their full model values). 
Figure 1: Irish investment fund performance since 2007 Indexed performance of the total market and each sector portfolio from July 2007 to September 2015

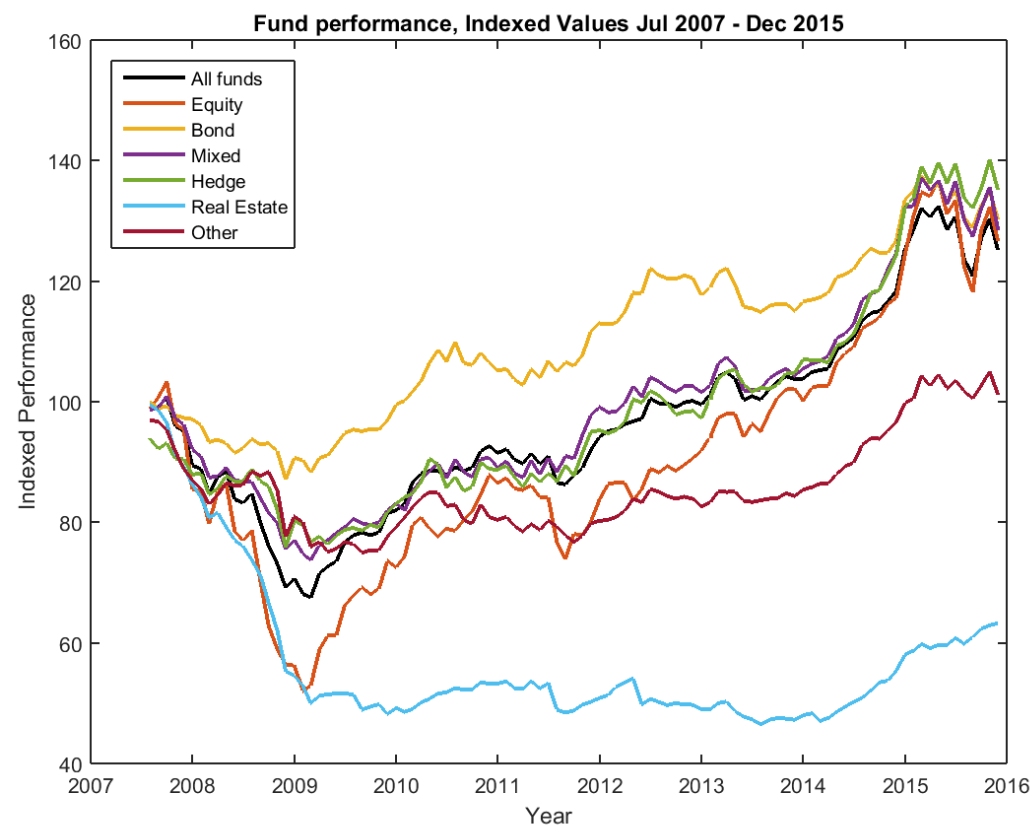

Figure 2: Non Parametric Distributions of the market and sector portfolios July 2007Dec 2015.

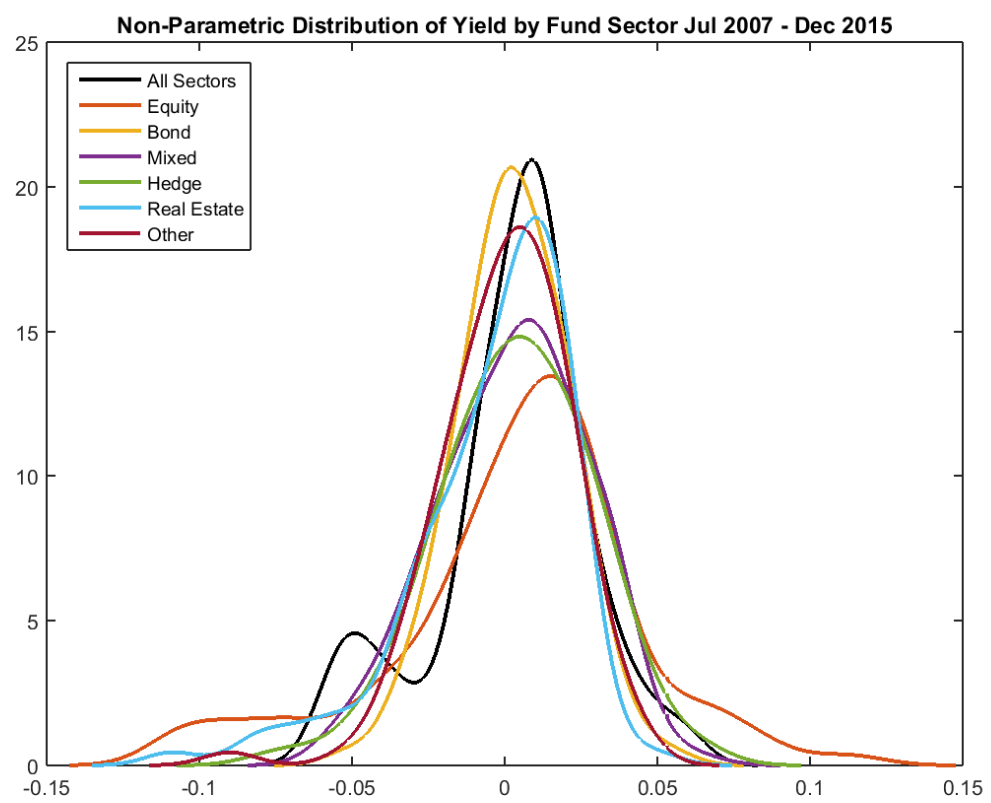


Figure 3: Non Parametric distributions (Jul 2007 - Dec 2015) The market portfolio and the market portfolio minus one sector. Illustrating the contribution of each sector to the tail of the distribution.

(a) Distribution minus Equity funds

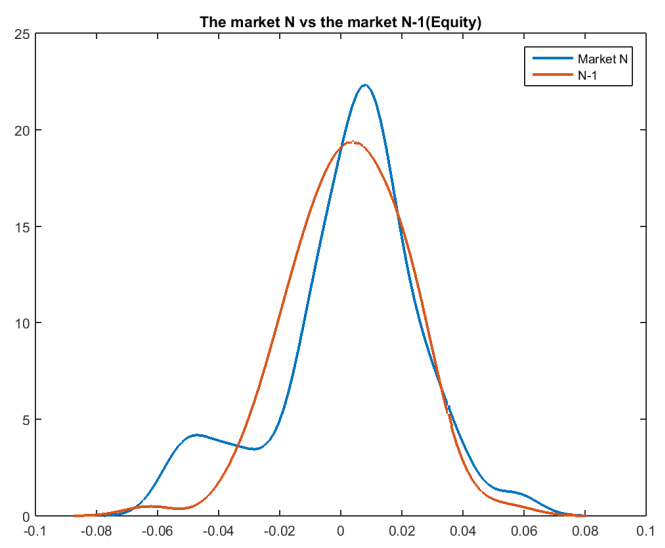

(b) Distribution minus Bond funds

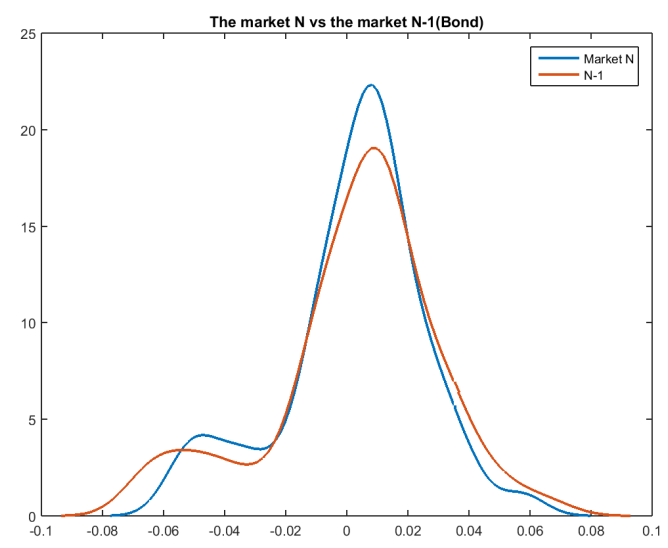


Figure 4: Full Sample 2007-2015 Volatility, Correlation

(a) Time series volatility estimate

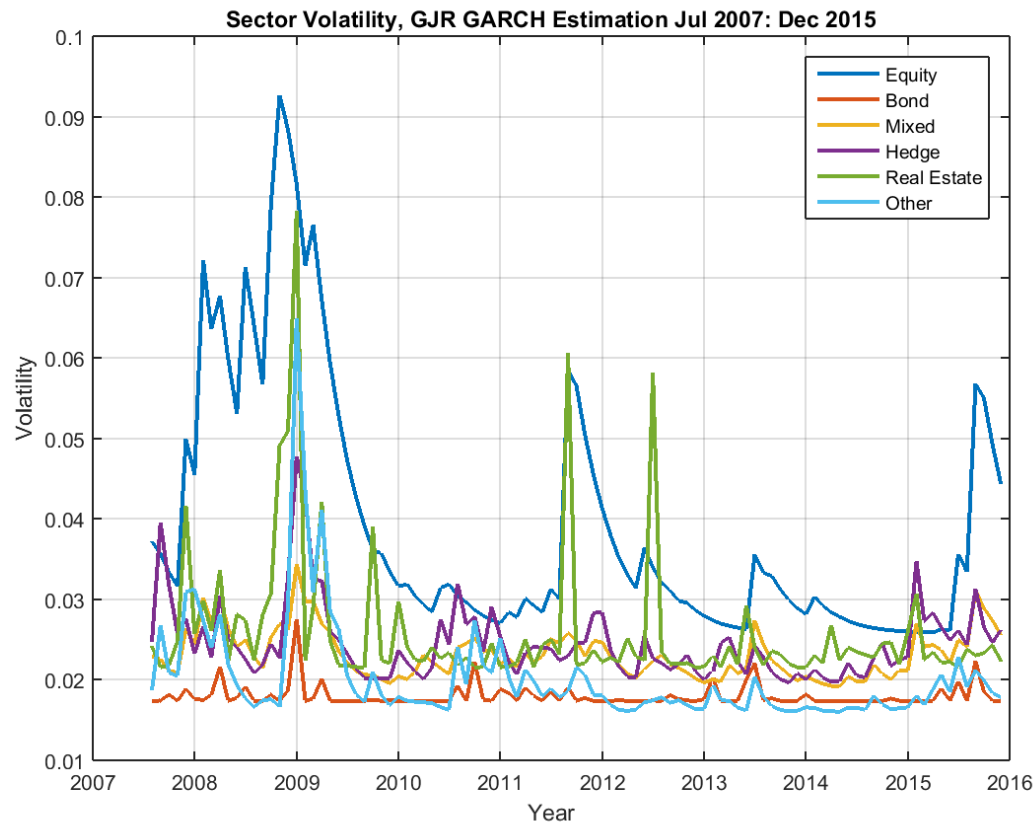

(b) Time series conditional correlation estimate

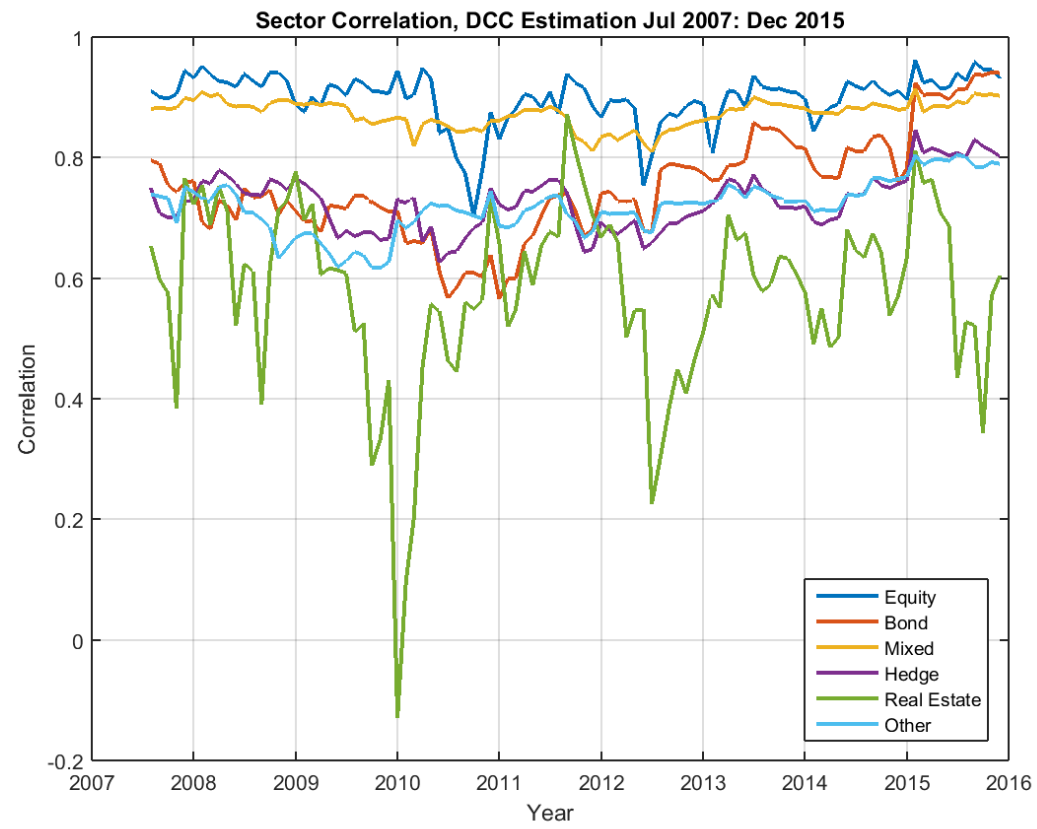


Figure 5: Time series estimate of Marginal Expected Shortfall for each sector portfolio between 2007-2015

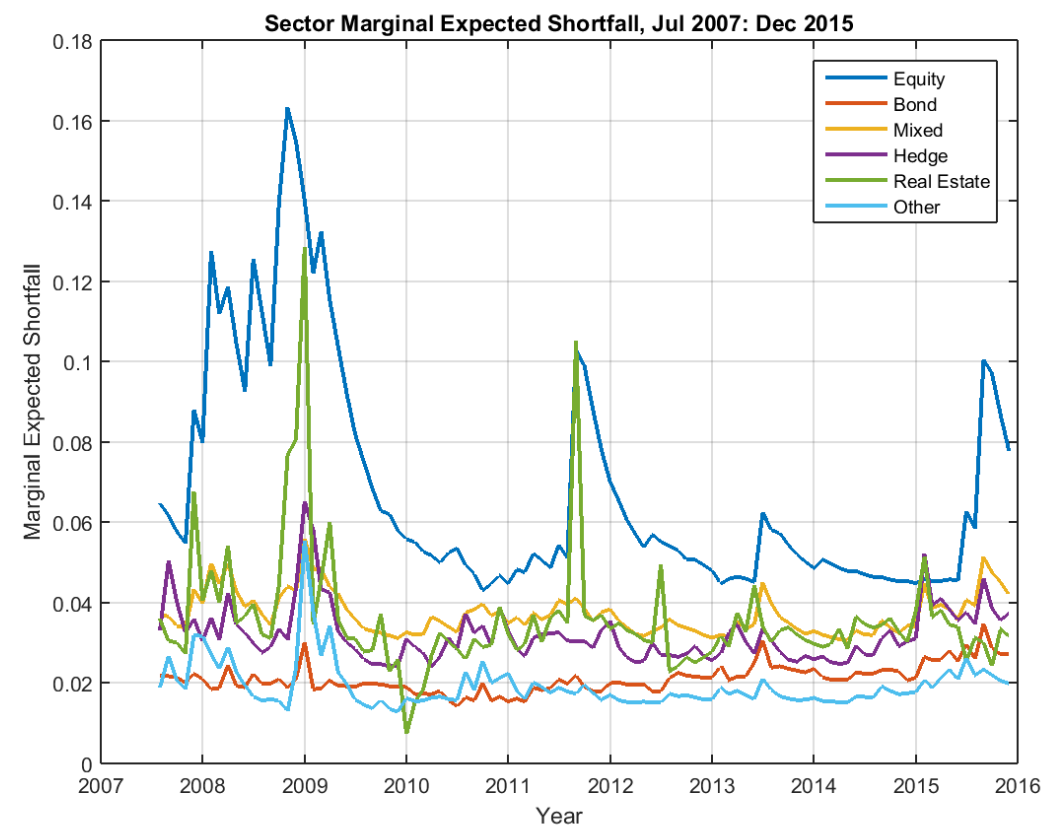


Figure 6: Conditional Beta Figure a provides a time series estimate of the time varying conditional beta estimated using the DCC GARCH estimates. Figure $b$ shows the mean beta plotted against the mean MES for each of the sector size portfolios.

(a) Time series conditional beta estimate

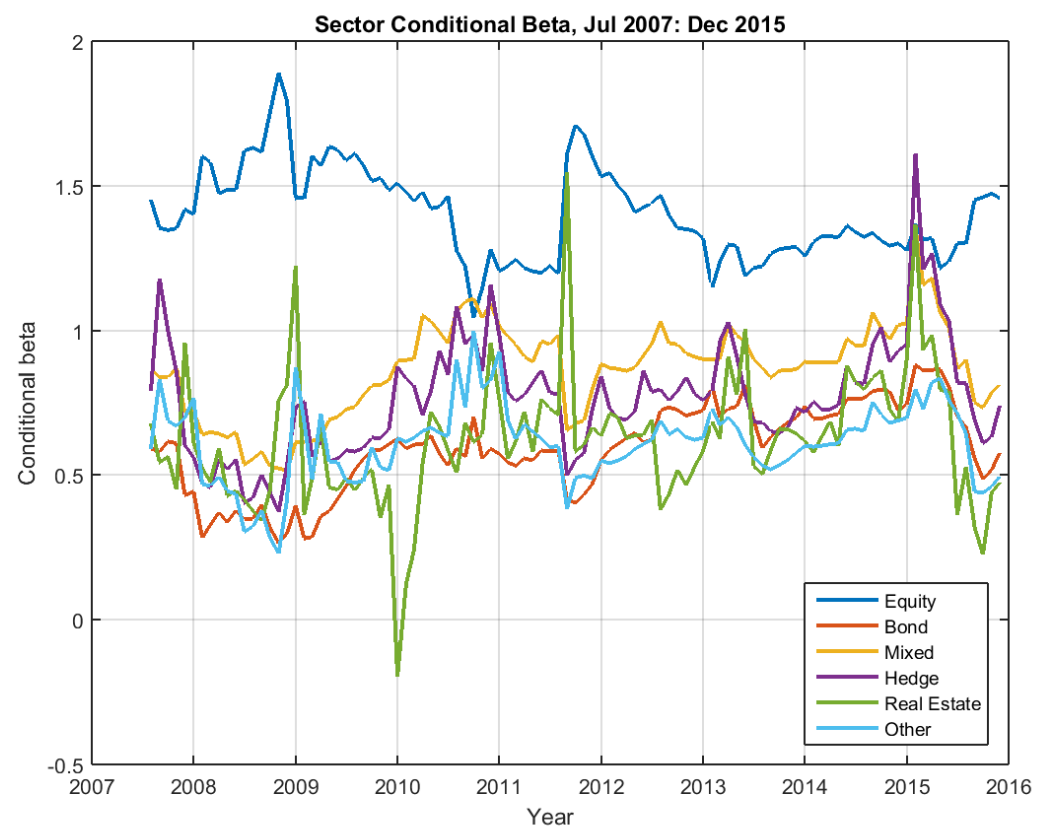

(b) Beta vs MES

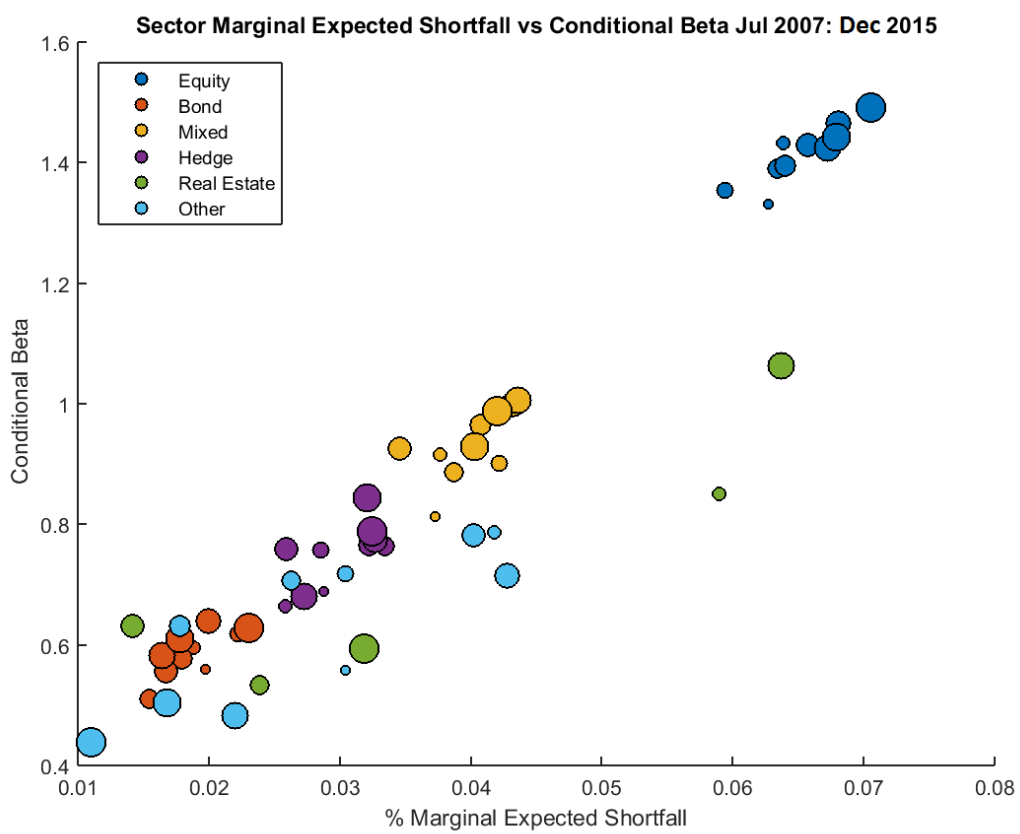


Figure 7: Yield vs Volatility Mean values for portfolios sorted by size for two periods, during the crisis (Jul 2007- Jun 2009) and post crisis (Jul 2009 - December 2015). Portfolio mean NAV return values plotted against the mean MES over the sample period where data point sizes represent the size of portfolios. Sectors sorted into deciles, due to low number of funds Real Estate funds are sorted into quintiles.

(a) Jul 2007- Jul 2009

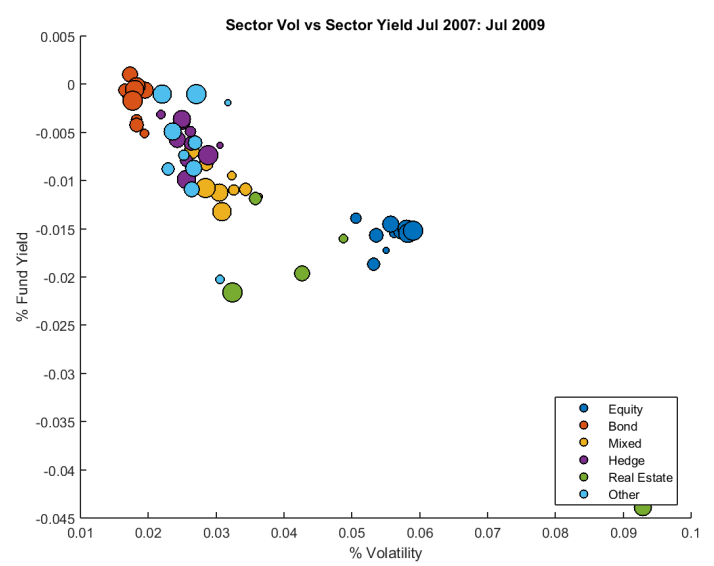

(b) Jul 2009 - Dec 2015

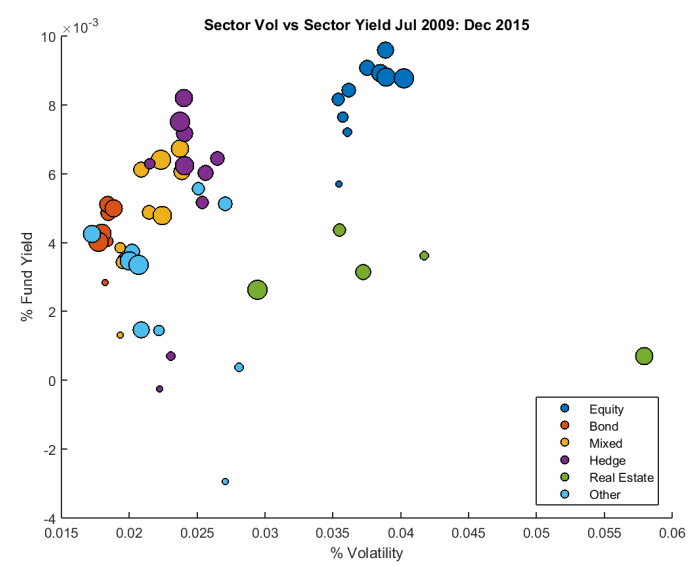

Figure 8: Yield vs Dynamic Conditional Correlation Mean values for portfolios sorted by size for two periods, during the crisis (Jul 2007- Jun 2009) and post crisis (Jul 2009 December 2015). Portfolio mean NAV return values plotted against the mean MES over the sample period where data point sizes represent the size of portfolios. Sectors sorted into deciles, due to low number of funds Real Estate funds are sorted into quintiles.

(a) Jul 2007- Jul 2009

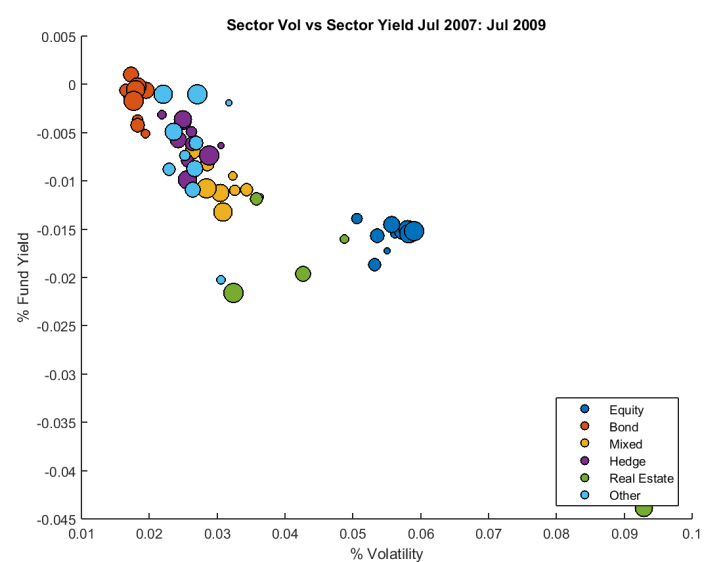

(b) Jul 2009 - Dec 2015

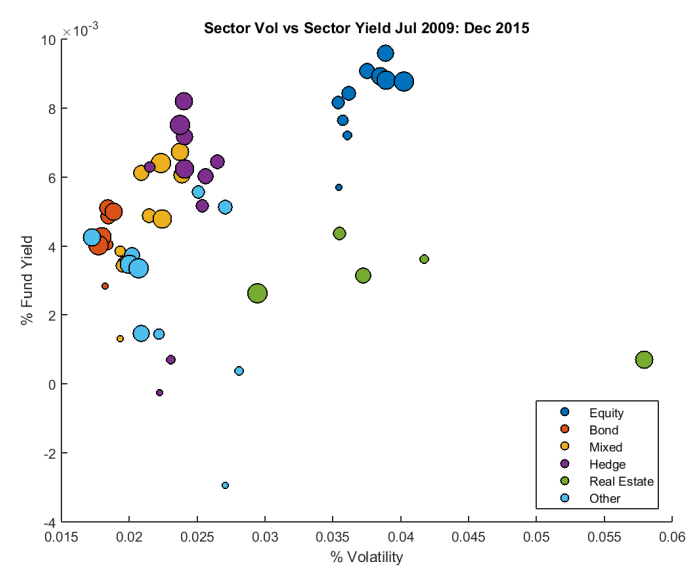


Figure 9: Yield vs Marginal Expected Shortfall Mean values for portfolios sorted by size for two periods, during the crisis (Jul 2007- Jun 2009) and post crisis (Jul 2009 December 2015). Portfolio mean NAV return values plotted against the mean MES over the sample period where data point sizes represent the size of portfolios. Sectors sorted into deciles, due to low number of funds Real Estate funds are sorted into quintiles.

(a) Jul 2007- Jul 2009

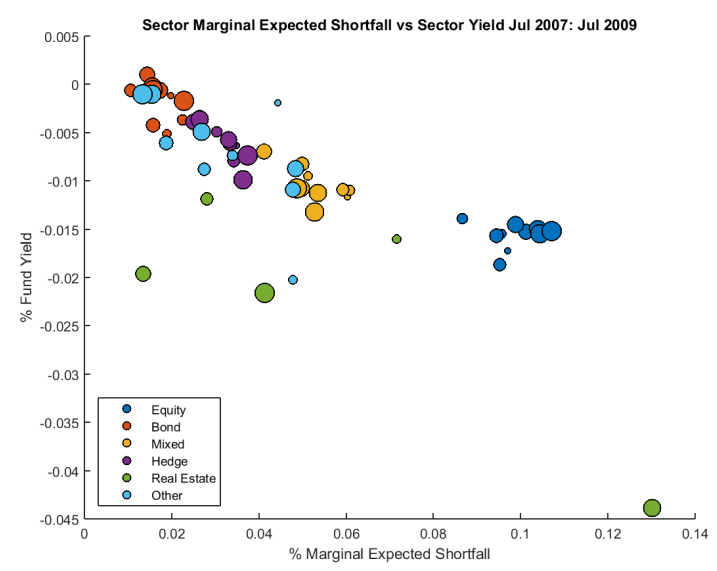

(b) Jul 2009 - Dec 2015

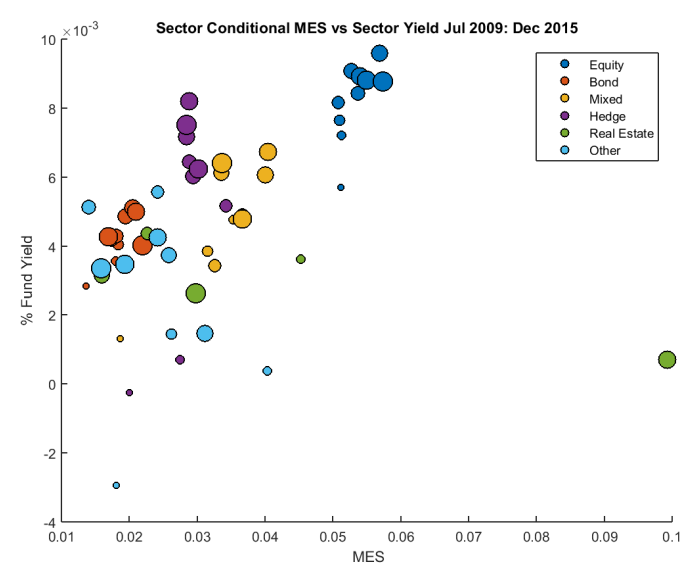

